\title{
Aquatic habitat use in a semi-aquatic mammal: the Eurasian beaver
}

\author{
Rasmus Mohr Mortensen ${ }^{1 *} \mathbb{D}$, Stefanie Reinhardt ${ }^{1}$, Marina Eraker Hjønnevåg ${ }^{1}$, Rory Paul Wilson ${ }^{2}$ and \\ Frank Rosell ${ }^{1}$
}

\begin{abstract}
Background: Semi-aquatic mammals exploit resources both on land and in water and may require both to meet their habitat requirements including food- and building resources, refuges, and for social interactions with conspecifics. Within this, the specific availability of both terrestrial and aquatic resources is expected to impact individual fitness. Beavers are highly dependent on water for movement and protection from predators. They are central place foragers and mostly forage on woody vegetation near water although aquatic vegetation may also be an important food resource. However, little is known about their use of aquatic habitats. We aimed to address this knowledge gap by dead-reckoning fine-scale movement tracks and classifying fine-scale diving events, which we then related to the spatial distribution of aquatic vegetation and habitat components within the territory.
\end{abstract}

Results: Overall, there was a statistically clear decrease in probability that diving would occur at dawn and with increasing distance from territory borders. In addition, the distance from the lodge at which animals dived decreased through the night and during the spring/early summer. There was strong selection for diving habitats located closer to the riverbank, with stronger selection for these areas being observed in individuals with larger home ranges. We saw a higher selection for diving above clay sediment, and within $150 \mathrm{~m}$ from the lodge, presumably because mud and clay sediment tended to be located closer to the lodge than sand and rock sediment. Furthermore, we found a clear selection for diving in the presence of quillwort (Isoetes spp.), shoreweed (Littorella uniflora), and stonewort (Nitella spp.). Selection for these focal species was stronger among subordinate individuals. Individuals with lower body condition dived closer to the beaver lodge, and dives located further from the lodge were associated with high densities of aquatic vegetation.

Conclusion: We provide new knowledge on the aquatic habitat use in a semi-aquatic mammal and show how energetic constraints may shape how beavers spatially use the aquatic environment, whereby short and shallow dives appear most beneficial. We show how aquatic habitats may have great importance for both foraging, building materials and safety, and discuss to how they may affect the fitness of individuals.

Keywords: Aquatic foraging, Behavioural ecology, Castor fibre, Dead-reckoning, Habitat selection, Movement ecology, Resource selection functions

\footnotetext{
*Correspondence: rmo@usn.no

${ }^{1}$ Faculty of Technology, Natural Sciences, and Maritime Sciences,

Department of Natural Sciences and Environmental Health, University

of South-Eastern Norway, Bø i Telemark, Norway

Full list of author information is available at the end of the article
}

\section{Background}

Animal movements are affected by a suite of factors, including the cost of movement [1-6], likelihood of predation [7-11], resource distribution [12-14], reproduction $[15,16]$, and social interactions [12, 17-19]. This, in part, explains why there is so much interest in animal movement ecology, but elucidating causality to explain original author(s) and the source, provide a link to the Creative Commons licence, and indicate if changes were made. The images or other third party material in this article are included in the article's Creative Commons licence, unless indicated otherwise in a credit line to the material. If material is not included in the article's Creative Commons licence and your intended use is not permitted by statutory regulation or exceeds the permitted use, you will need to obtain permission directly from the copyright holder. To view a copy of this licence, visit http://creativecommons.org/licenses/by/4.0/. The Creative Commons Public Domain Dedication waiver (http://creativeco mmons.org/publicdomain/zero/1.0/) applies to the data made available in this article, unless otherwise stated in a credit line to the data. 
animal movement is challenging as behavioural ecologists have to juggle with multiple interacting factors [20, 21].

A major movement delimitator results from competition, when animals may exclude potential competitors from an area by being territorial [22, 23]. As a result, some individuals end up defending habitats that do not have favourable combinations of essential resources, and thus have to trade-off resources within their ultimate habitat acquisition [24-26]. Consequently, some species benefit by being generalists rather than specialists, because the consequences of losing a resource are less severe since animals can exploit a greater variety of resources [27-30]. For example, semi-aquatic mammals have adapted to exploit resources on land and in water, and individuals of this group may express considerable plasticity to meet their habitat requirements according to the available food resources, shelter, and social interactions [31-33].

Habitat selection happens at various spatial scales [34] and is described as the use of resources (habitat) in a manner that is disproportionate to their availability [35]. Critically, resource-use may not necessarily be directly proportional to resource availability, but it may also be modulated by other ecological factors such as competition and predation [25,36-38]. Although it has always been a challenge to quantify which habitats animals have available to them, and how much they use them, today, this information is important to inform space-value discussions so that confounding ecological variables affecting habitat value for the animal can be put into context [39-41].

In this study, we examine aquatic habitat use in Eurasian beavers (Castor fibre) to identify important characteristics of aquatic habitats within beaver territories and investigate potential differences in aquatic habitat use among individuals. To achieve our aim, we combine sophisticated animal-attached tags (GPS loggers and Daily Diary units), that allow determination of animal behaviour with locations, with a comprehensive assessment of aquatic habitat characteristics.

Technological developments have hugely enhanced what animal biotelemetry can do for us, elucidating, for example, fine-scale spatiotemporal location data on an increasing range of animals across various environments [40-43]. In particular, tri-axial accelerometers are increasingly being used to study wild animals [44, 45], because they allow determination of an individual's behaviour [46]. They have been used to classify behaviour and activity level patterns in beavers, distinguishing seven behaviours with high precision, including swimming and diving $[47,48]$. These behaviours can be combined with fine-scale animal movement determined by dead-reckoning [49-51] to provide information on what animals do in the spaces they inhabit [52]. Altogether, fine-scale information on behaviour and movement, obtained from the use of acceleration and dead-reckoning, respectively, are being used increasingly to study wild animals that are hard to observe directly and/or without bias [44, 49, 52-56].

Beavers are socially monogamous, monomorphic, nocturnal mammals that inhabit various freshwater bodies [38, 57]. They live in family groups consisting of the dominant breeding pair, kits of the year, and older non-breeding offspring [33, 58, 59]. Beavers reach sexual maturity during their second winter [59], and give birth to one to five kits in mid-May at northern latitudes [57]. The kits emerge from the lodge in July when they start feeding on their own [33]. At around 2-3.5 years old, beavers tend to disperse from their natal territory to establish their own territory $[15,60]$.

Beavers are central place foragers, mostly foraging near water and their lodges [61-63]. Their diet consists mainly of woody vegetation but varies seasonally, and comprised primarily bark from deciduous trees during winter to more nutritiously rich deciduous leaves, aquatic vegetation, and herbaceous plants in spring and summer [6472]. In some areas, aquatic plants may seasonally account for up to $90 \%$ of the diet $[65,66,73]$. Aquatic vegetation may offer some nutritional benefits over terrestrial vegetation, including better digestibility, higher crude protein, and higher sodium and iron content $[64,66,74,75]$. Low concentrations of secondary compounds might also make aquatic vegetation more palatable [66], but this may vary with species [76]. Seasonally, rhizomes of aquatic plants can provide great nutritional value in winter and spring when plants store nutrients in the rhizomes in preparation for spring growth $[77,78]$. Diet variation may depend on nutrient content and digestibility of available forage as individual beavers attempt to maximize energy intake over time [66, 76, 79-81]. Beaver foraging behaviour varies according to environmental factors that affect the distribution of food items [82], but ecological factors such as food plant density, human disturbance, presence of conspecifics, and predator activity may also affect their foraging choices and foraging locations [67, 83, 84]. No clear dietary differences have been found between sexes, ages, or social ranks in beavers $[65,69,85]$, but several studies indicate that foraging behaviour may differ seasonally as territorial movements vary among individuals [86-88]. Furthermore, individuals may be affected by various ecological conditions during their lifetime, such as loss and acquisition of territories [15, 89], that can affect their behavioural time-budgets and consequently their body condition, reproduction, and survival [57, 90]. 
Water acts as a refuge for beavers [91] and is specifically used to minimize predation risk when foraging on land [92]. Even though beavers depend on the aquatic environment for movement and safety [83, 86, 87, 93] and may even manipulate the environment to optimize aquatic conditions [82, 94], aquatic behaviour and habitat use have not been well studied in these animals. Although beavers use aquatic habitats for foraging [64-66, 71], protection from predators $[92,95]$, and collecting resources for lodge- and dam-building [96, 97], aquatic habitats may be particularly important when terrestrial vegetation is difficult to access, or is of low nutritional quality [38, $64,66,75,98]$. However, their spatial exploitation of the aquatic components of their territory is poorly understood. Research has found, however, that habitat use may differ between age groups and according to risk levels [87]. Diving behaviour has been studied using accelerometers, which has highlighted a preference for short $(<30 \mathrm{~s})$ and shallow (up to $4 \mathrm{~m}$, but most $<1 \mathrm{~m}$ ) dives, which indicate some form of aquatic resource selection, although the link between diving and space use is vague [99]. Being only semi-aquatic [cf. 100], beavers may experience a higher cost exploiting aquatic resources [101, 102] than a fully aquatic equivalent may do. This may explain why studies have found them to be diving for less than $3 \%$ of their nightly activity budget [99]. However, energy requirements have been reported to compare well with more fully aquatic mammals and birds [101].
Using fine-scaled dead-reckoned animal tracks to determine spatial and temporal locations of aquatic dives, we aim to examine important characteristics of aquatic habitat use by Eurasian beavers and investigate potential individual differences. Assuming that dives indicate aquatic habitat use in beavers, we hypothesize that habitat use vary temporally and spatially between individuals of various ages, sexes, social ranks, and by the composition of biotic and abiotic factors within their individual territories.

\section{Methods \\ Study site}

Our study site was located at the lower reaches of the river Sauar in Vestfold and Telemark County, southeastern Norway (Fig. 1). The river drains the lake Heddalsvatnet in the north and forms part of the catchment of the lake Norsjø in the south, stretching over approximately $13 \mathrm{~km}$ with a width of $45-250 \mathrm{~m}$. The river sections are generally slow-flowing with stable water levels because of natural lakes and man-made impoundments along part of its length [103], although flooding events frequently occur. The river flows through small villages, farmlands and fields interspersed with riparian woodland that comprised mostly Norway spruce (Picea abies), Scots pine (Pinus sylvestris), birch (Betula spp.), grey alder (Alnus incana), aspen (Populus tremula) and mountain ash (Sorbus aucuparia) [62, 103].
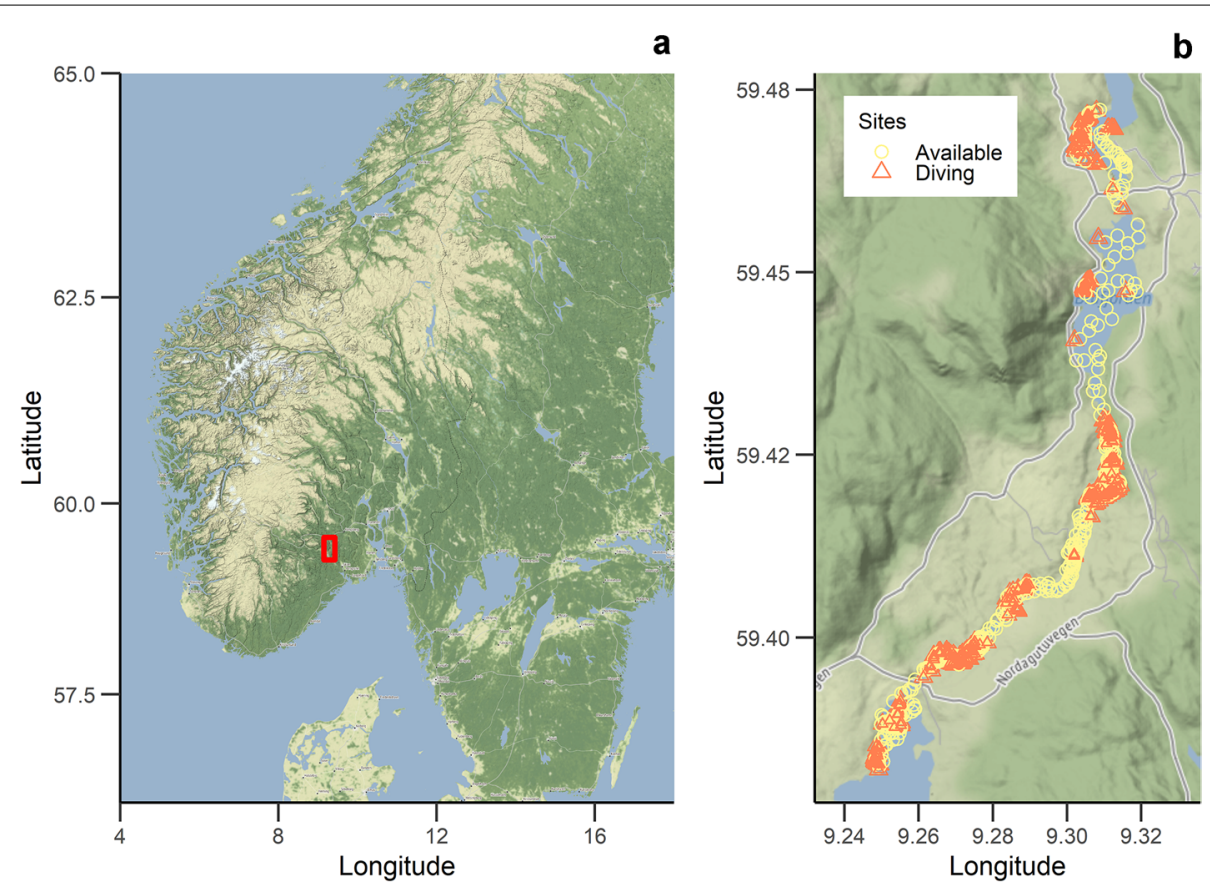

Fig. 1 a The location of the study site (red square) in Telemark and Vestfold County, Norway. b Overview of study river with random available sites (yellow circles) and identified beaver diving locations (red triangles) within beaver territories 
Beavers have inhabited the area since the 1920s when they recolonized the rivers [104]. The population is at carrying capacity, as territories of various sizes directly border each other [33]. Territory borders are identified based on scent mound concentrations, sight observations of known patrolling beavers backed up by GPS data. The main river contains ten distinguishable territories inhabited by approximately 32 individuals [33, 57]. Predation pressure is low as wolves (Canis lupus) and bears (Ursus arctos) are functionally extinct in the area, and lynx (Lynx $l y n x)$ only occur at low densities [84, 105].

The study river is part of a larger monitoring project where beavers in the area have been monitored through an extensive capture programme, the Norwegian Beaver Project (NBP), since 1997 [57]. The long-term monitoring project aims to capture all newcomers (kits and dispersers from outside the study site) annually, enabling identification of individuals at later encounters and family group sizes.

\section{Capture and tracking protocol}

Individuals were detected from a motorboat using searchlights and captured at night with large divingnets in shallow water or with land-nets [106]. Captured individuals were immobilized in cloth sacks, enabling easy handling without anaesthesia, and identified via microchips (PIT tag) and unique combinations of plastic and metal ear-tags. Beavers were weighed to the nearest $100 \mathrm{~g}$. Body length was measured following the curvature of the spine from nose tip to the base of the tail. Tail length was measured from the base to the tip of the tail, and tail width was measured from edge to edge of the dorsal surface at the midpoint between tail base and tip. Measurements of body length and tail proportions in $\mathrm{cm}$ were used to calculate tail fat index ((tail length $\times$ tail width)/body length), representing the body condition of beavers [57, 59].

Individuals were sexed based on the colour and viscosity of their anal gland secretion [107] and assigned a minimum age based on body mass at first capture [57, 108]; minimum 2 years (subadult) when body mass was between 17 to $19.5 \mathrm{~kg}$ inclusive, and minimum 3 years (adult) when body mass was above $19.5 \mathrm{~kg}$. Territorial dominance was in most cases attributed to adult territorial residents of each sex. Territorial dominance was verified by eventual dispersal of the alternative candidate, greatest body weight among same-sex group members or lactation in females (large nipples, i.e. $>0.5 \mathrm{~cm}$ ). Individuals dispersing into a territory were posited to have achieved the dominant breeding position when the previous dominant same-sex individual had disappeared, or evidence outlined above was applicable. Unless proven otherwise, dominant individuals were assumed to maintain their social rank until they died or disappeared from the territory [109].

We captured and equipped nine beavers (five males, four females, Table 1) with GPS loggers (Gipsy-5, Techno Smart) and daily diary units (including accelerometer, magnetometer, thermometer, Wildbyte technologies [52]) in the spring and early summer of 2018 (one beaver) and 2019 (eight beavers). The data loggers were glued onto the fur on the lower back of the beavers, approximately $15 \mathrm{~cm}$ above the tail following the spine, and were removed again after 2 to 3 weeks if they had not fallen off by themselves [47]. To extend battery life, GPS loggers were programmed to take a fix position every $15 \mathrm{~min}$ between 7 p.m. and 7 a.m. to reduce numbers of unsuccessful GPS fix attempts from within the beaver lodges. Daily diary units logged continuously at $40 \mathrm{~Hz}$. From the GPS positions, we identified territory borders to estimate territory size, expressed in bank length $(\mathrm{km})$ and calculated 95\% autocorrelated kernel density estimates (AKDE) to estimate the overall space use (home range) of each beaver [110]. Captured beavers were released near the capture site within their territory after approximately $40 \mathrm{~min}$ of handling time [106].

\section{Identification of dives}

Accelerometers in tandem with magnetometers can be used in dead-reckoning to accurately predict and reconstruct animals' fine-scale three-dimensional movement paths in space and time by sequentially integrating calculated travel vectors $[49,51]$. However, the estimated movement track accumulates error and therefore drifts over time, so it needs to be corrected through groundtruthing, e.g. correcting the track according to GPS fixes [49].

We calibrated the daily diary data in the software DDMT (Daily Diary Multiple Trace, Wildbyte Technologies). Using the acceleration and magnetism data, we dead-reckoned the movement track of each beaver in the software Framework4 [111]. The dead-reckoned movement tracks were hereafter corrected using the GPS positions as ground-truthing [49]. GPS positions were filtered to remove positions with horizontal dilution of precision (HDOP) values above five and with less than four available satellites to reduce the effects of imprecise GPS positions [112, 113].

To identify diving locations, we divided the dead-reckoned movement tracks into ten second bursts and used the acceleration to assign behavioural activities to each burst based on the acceleration-based behavioural classification model by Graf et al. [47]. The classification model can clearly differentiate the acceleration between seven behaviours: swimming, diving, sleeping, feeding, standing, walking, and grooming. To furthermore filter out 


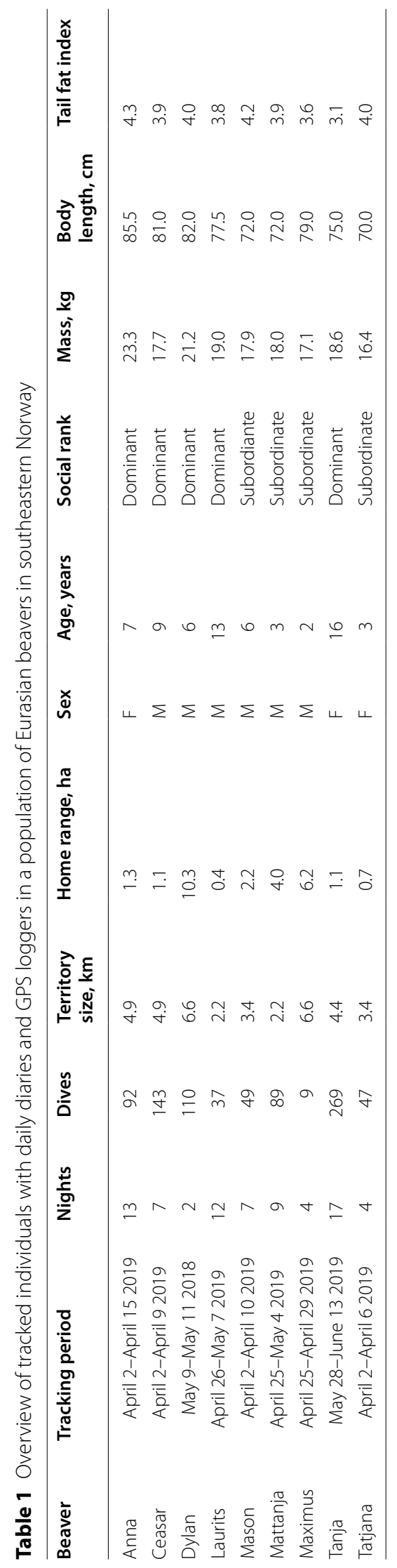


potentially falsely classified dives, we focused on diving sections where the previous 10-s bursts were additionally predicted to be swimming.

\section{Assessment of aquatic habitats}

We visited and assessed the aquatic habitat of all diving locations as well as random aquatic locations available within the territories of each beaver between June and October 2019 (Fig. 1b). We only sampled sites with a water depth of less than $10 \mathrm{~m}$ since vegetation growth here is more abundant due to light conditions [114], whilst also accounting for known diving depths in beavers [99].

For vegetation sampling at each location, sites were sampled using a $1 \times 1 \mathrm{~m}$ quadrat with an aluminium frame. The quadrat was placed as close to the location as wind and currents allowed. The frame construction had a pyramidal shape, enabling a GoPro camera (GoPro Hero5) to be attached to the top, $0.8 \mathrm{~m}$ above the surface, which would keep the quadrat within the camera view. The quadrat was left at the bottom of the site after sediment settled, and pictures and films were recorded. When water depth allowed it, aquatic plants and physical characteristics were recorded in situ using an aqua scope. Aquatic plants were collected with a rake when identification required closer inspection. Plant species identification followed the database of Artsdatabanken [115]. Species abundance was quantified as coverage in percentage, rounding to the nearest 5\% [116]. Plants with less than $5 \%$ cover were registered as $1 \%$ per species.

We categorized each site according to physical characteristics [water depth and sediment type (clay, mud, sand, and rock)], spatial characteristics (distance to riverbank, beaver lodge, and territory border), and characteristics of the aquatic vegetation. We characterized the aquatic vegetation by cover and species richness (number of species) to evaluate importance of quantity and diversity, respectively.

\section{Statistical analysis}

We used generalized linear mixed-effects models (GLMMs) with Poisson distribution, log link, and beaver ID as a random effect to investigate how the number of identified dives per night varied between individuals and components of the territories. We analysed the effects of sex (male, female), social rank (dominant, subordinate), age (years), body size (body mass, body length, and tail fat index), and home range size (95\% AKDE), and the effects of territory size (bank length in $\mathrm{km}$ ), mean water depth $(\mathrm{m})$ and mean vegetation cover and species richness.

Using GLMMs with Bernoulli distribution, logit link, with beaver ID and tracking night as random effects, we also investigated how hourly diving probability $(1=\mathrm{a}$ diving event was identified within a given hour, $0=$ no diving events were identified within a given hour) varied through the night and between individuals. We analysed the effects of spatiotemporal variables (date, hour of the night, distance to riverbank, lodge, and territory border), individual differences (sex, social rank, age, body sizes, and home range size), and between components of the territories (territory size, mean water depth, mean vegetation cover, and mean species richness).

We used a detrended correspondence analysis (DCA) from the R package 'vegan' v. 2.5-7 [117] to assess the general distribution pattern of the aquatic vegetation in the study river in relation to physical (water depth and sediment type), spatial (distance to riverbank, beaver lodge, and territory border) and vegetation characteristics (vegetation cover and species richness) of the sites. A matrix including aggregated abundance per species was used for the DCA. However, species that only occurred in five sites or less were removed from the matrix. The correlation between the aquatic species compositions and physical, spatial, and vegetation characteristics of the sites were assessed by passively fitting them to the ordination (permutations $=999$ ). From the ordination, comparing species with use, we could furthermore identify species that appeared to be of potential importance to the beavers when diving. For the subsequent resource selection functions, we included variables for the number of focal species present at a site and vegetation cover of these focal species.

We investigated the aquatic habitat selection within territories using GLMMs with Bernoulli distribution, logit link, and beaver ID as a random effect $(1=$ diving site, $0=$ random available site within the territory) [34, 35]. We analysed whether aquatic habitats located at varying water depths, sediment types, distances to riverbank, beaver lodge, and territory border, or with varying vegetation cover (overall and focal species), and species richness (overall and focal species) were used more than was generally available in the territories $[35,118]$. Additionally, we analysed the variations in diving selection among individuals in univariate models weighted by number of identified dives by fitting the resource selection function to each individual [119]. This enabled us to analyse how the individual diving selection coefficients varied between beavers of different age, sex, body size, and social rank that furthermore inhabit territories of different size and with varying amount of available water depth, vegetation cover (overall and focal species), and species richness (overall and focal species) $[13,25,119]$. As dives may have different purposes according to their spatial location, we furthermore investigated how log transformed distance to the lodge and riverbank varied temporally (date and hour of the night), by environmental 
characteristics (depth, sediment, vegetation cover, species richness), and among individuals of different age, sex, body size, social rank, territory size, and home range by using GLMMs with gaussian distribution and beaver ID as a random effect. To examine characteristics associated to the proximate area of the beaver lodge, we furthermore analysed how dives within $150 \mathrm{~m}$ of the beaver lodge varied according to the above variables using univariate GLMMs with Gaussian distribution and beaver ID as a random effect.

In all analyses, a list of candidate models was created using ecologically relevant combinations of fixed effects to account for variability in endogenous (such as sex, age, and social rank) and exogenous factors (such as territory size, vegetation composition) that may be important in describing the ecology of beavers (Fig. 2). Because of the sample size, individual effects (sex, age, social rank, territory size, and home range size) should be interpreted with care as they only imply possible ecological effects that should be investigated with more individuals in future studies. We included spatiotemporal interactions (between hour and distance to riverbank, lodge, and territory border, respectively) in the analysis for diving probability, but excluded interactions in all other analyses because of the limited sample size. Individual selection coefficients were similarly analysed in univariate models because of the limited sample size. The fixed effects used in all analyses were not correlated (Pearson $r$ coefficients less than 0.5 ) and variance inflation factor values were less than 3 [120].

Model selection was based on Akaike's information criterion corrected for small sample size [121], and carried out using the R packages 'glmmTMB' v. 1.0.2.1 [122] and 'MuMIn' v. 1.43.17 [123]. The most parsimonious models within $\triangle \mathrm{AICc}<2$ were chosen as the best models to describe the variation [121, 124]. In each model, variables that included zero within their 95\% confidence interval $(\mathrm{CI})$ were considered uninformative and reported as unclear effects [124]. The best models were visually validated using the $\mathrm{R}$ package 'DHARMa' v. 0.4.1 [125] to plot standardized model residuals against the fitted values [120] and, when relevant, furthermore checked for zero-inflation. Top candidate models for all analyses can be found in the supplemental material (Additional file 1). All analyses were conducted in R 4.0.3 [126].

\section{Results}

Nine beavers were tracked with data loggers (Wildbyte technologies, Daily Diaries [52]) and GPS loggers (Techno Smart) affixed to the lower back for a total of 77 nights. Identified diving events lasted between 10 and $110 \mathrm{~s}$, with the majority $(80 \%)$ lasting $10 \mathrm{~s}$ or less. We identified on average (mean \pm SD) $9.5 \pm 3.1$ dives per night for each beaver. We found no clear differences in the number of dives per night between males and females $(10.9 \pm 3.3$ and $8.8 \pm 3.0$, respectively), among dominants and subordinates $(12.9 \pm 3.6$ and $6.4 \pm 2.5$, respectively) or as a function of age, body size and tail fat index (Additional file 1). Furthermore, territory size, home range size, mean water depth in territory, and mean vegetation cover and species richness in territory did not have a clear effect on the number of identified dives per night (Additional file 1).

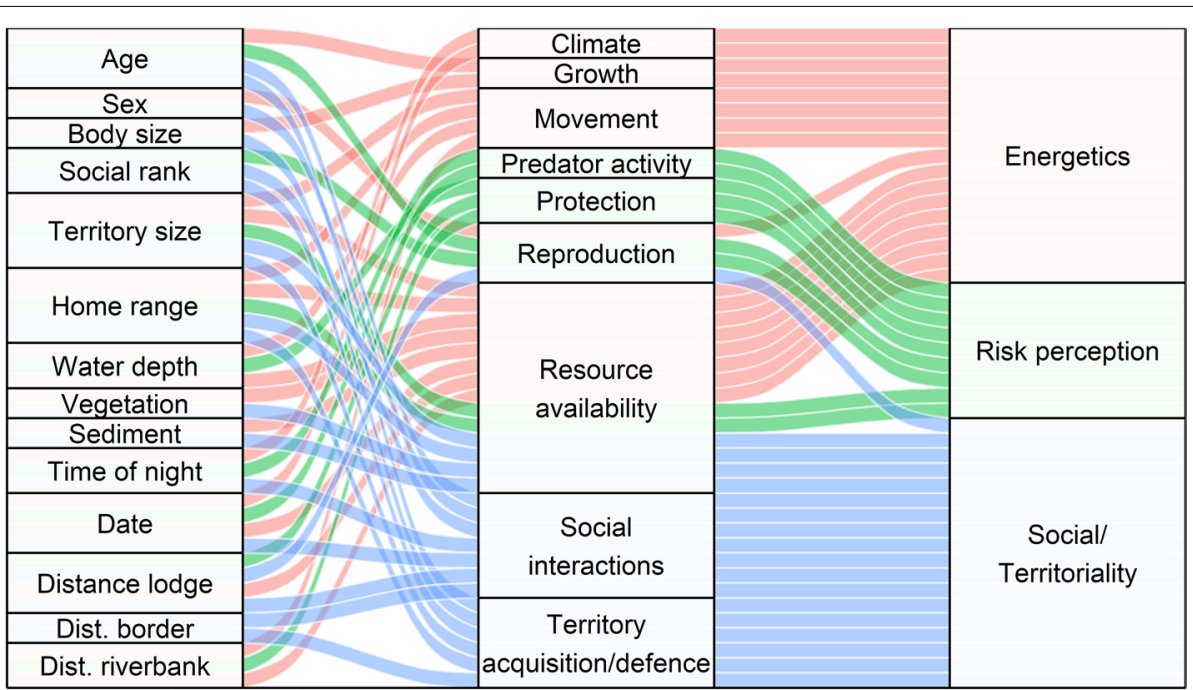

Fig. 2 Alluvial diagram showing how covariates included in the analyses (left) may relate to various ecological mechanisms (middle) which ecologically may have physical, behavioural, and social consequences (right) for the fitness of beavers 


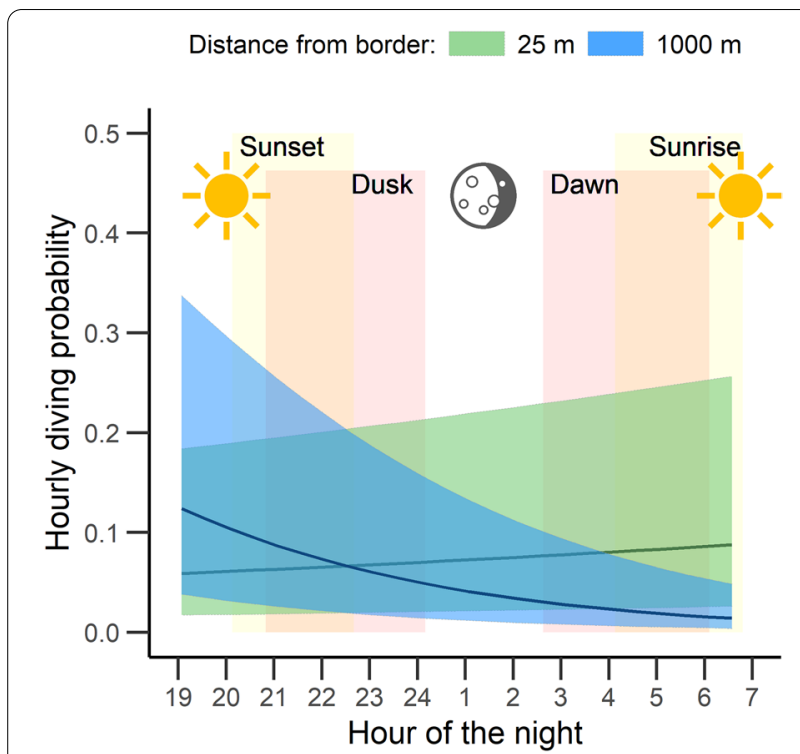

Fig. 3 The predicted relationship $\pm 95 \%$ confidence interval between hourly diving probability, time of night, and distance from territory border among nine individuals in a Eurasian beaver population in southeastern Norway. Yellow boxes represent time of sunset and sunrise through the tracking period. Red boxes represent time of dusk and dawn through the tracking period

Table 2 Effect size $(\beta)$, standard error (SE), lower ( $\mathrm{LCl}$ ) and upper (UCI) $95 \%$ confidence interval of explanatory variables for the analysis of nightly diving probability among nine individuals in a Eurasian beaver population in southeastern Norway

\begin{tabular}{|c|c|c|c|c|}
\hline Variable & Estimate $\beta$ & SE & $\mathrm{LCl}$ & $\mathrm{UCl}$ \\
\hline Intercept & -2.970 & 0.652 & -4.247 & -1.692 \\
\hline Hour & -0.114 & 0.002 & -0.119 & -0.110 \\
\hline $\begin{array}{l}\text { Log (distance to } \\
\text { territory border) }\end{array}$ & -0.184 & 0.007 & -0.197 & -0.171 \\
\hline $\begin{array}{l}\text { Hour } \times \log \\
\text { (distance to ter- } \\
\text { ritory border) }\end{array}$ & -0.064 & 0.002 & -0.069 & -0.059 \\
\hline Marginal $\boldsymbol{R}^{\mathbf{2}}: 0.01$ & \multicolumn{4}{|c|}{ Conditional $\boldsymbol{R}^{2}: 0.84$} \\
\hline
\end{tabular}

Effects were modelled using a GLMM with Bernoulli distribution. Beaver ID and tracking night were included as random effects. Informative parameters are given in bold

\section{Diving probability}

Hourly diving probability varied through the night, decreasing over the final hours of the night (Fig. 3) and with increasing distance from the territory borders (Table 2, Fig. 3). We found no differences in hourly diving probability between sexes, social ranks, age, or relative to body size and tail fat index. Furthermore, we found no clear effect of date, distance to riverbank, distance from the lodge, territory size, home range size, mean water
Table 3 Detrended correspondence analysis results for aquatic vegetation sites in a population of Eurasian beaver in southeastern Norway

\begin{tabular}{lcccc}
\hline & DCA1 & DCA2 & DCA3 & DCA4 \\
\hline Eigenvalues & 0.62 & 0.60 & 0.43 & 0.42 \\
Axis lengths & 6.15 & 4.94 & 4.30 & 3.51 \\
Proportion explained \% & 9.63 & 9.39 & 6.78 & 6.52 \\
Cumulative prop. explained \% & 9.63 & 19.02 & 25.80 & 32.32 \\
\hline
\end{tabular}

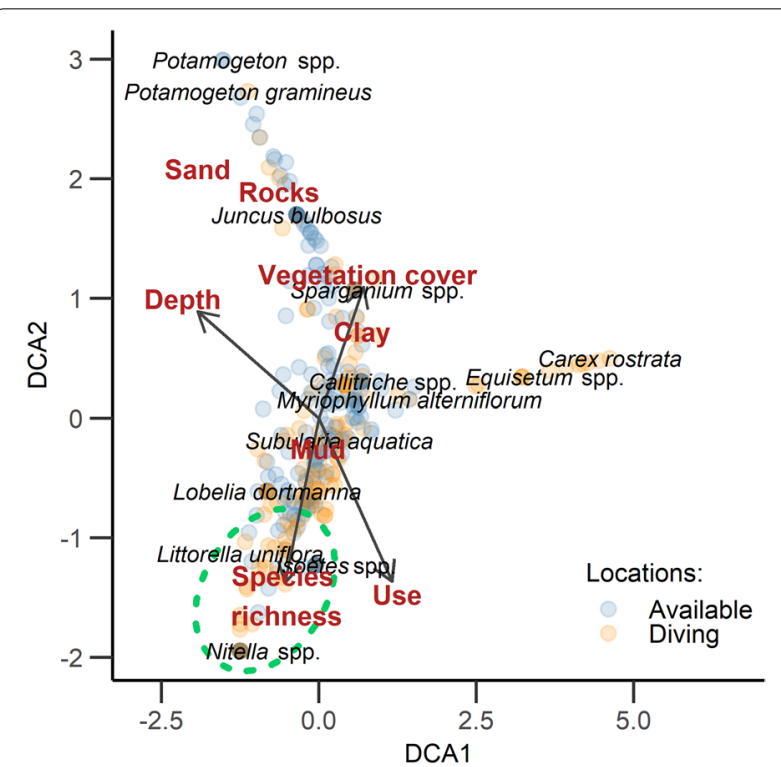

Fig. 4 Detrended correspondence analysis (DCA) of aquatic vegetation sites (points) within territories of nine individuals in a Eurasian beaver population in southeastern Norway. Arrows represent passively fitted environmental gradients and red labels represent environmental centroids. The green ellipse encircles species that may represent important resources at diving locations of the beavers

depth in territory and mean vegetation diversity within the territory on nightly diving probability (Table 2, Additional file 1).

\section{Characterization of aquatic vegetation}

The DCA ordination described up to $32.3 \%$ of the variation in the aquatic vegetation composition within the beaver territories with DCA1 and DCA2 describing 9.6 and $9.4 \%$ of the variation, respectively (Table 3 ). The aquatic vegetation within the territories showed great variation and differed clearly with increasing water depth, vegetation cover, species richness, and sediment type (Fig. 4). Diving sites and random available sites within the beaver territories clearly differed in species composition. Diving sites were especially associated with varying 
amounts of quillwort (Isoetes spp.), shoreweed (Littorella uniflora), and stonewort (Nitella spp.) (Fig. 4). Furthermore, sites were predominantly more used for diving

Table 4 Effect size $(\beta)$, standard error (SE), lower (LCI) and upper (UCI) 95\% confidence interval of explanatory variables for the analysis of diving location selection among nine individuals in a Eurasian beaver population in southeastern Norway

\begin{tabular}{lllll}
\hline Variable & Estimate $\boldsymbol{\beta}$ & SE & LCI & UCI \\
\hline Intercept & $-\mathbf{0 . 9 3 4}$ & $\mathbf{0 . 2 1 6}$ & $-\mathbf{1 . 3 5 8}$ & $-\mathbf{0 . 5 1 0}$ \\
Log (distance to riverbank) & $-\mathbf{0 . 6 8 6}$ & $\mathbf{0 . 0 8 6}$ & $-\mathbf{0 . 8 5 5}$ & $-\mathbf{0 . 5 1 7}$ \\
Sediment $_{\text {Clay }}$ & $\mathbf{0 . 8 5 7}$ & $\mathbf{0 . 2 6 5}$ & $\mathbf{0 . 3 3 7}$ & $\mathbf{1 . 3 7 6}$ \\
Sediment $_{\text {Sand }}$ & -0.349 & 0.308 & -0.952 & 0.254 \\
Sediment $_{\text {Rocks }}$ & -0.461 & 0.286 & -1.022 & 0.100 \\
Number of focal species & $\mathbf{0 . 3 4 0}$ & $\mathbf{0 . 1 4 1}$ & $\mathbf{0 . 0 6 5}$ & $\mathbf{0 . 6 1 6}$
\end{tabular}

present

Marginal $R^{2}: 0.19$ Conditional $R^{2}: 0.26$

Effects were modelled using a GLMM with Bernoulli distribution. Beaver ID was included as random effect. Informative parameters are given in bold

Reference level for sediment $=$ Mud with decreasing water depths, increasing species richness, and decreasing vegetation cover. A list of all aquatic species can be found in Additional file 1.

\section{Resource selection of aquatic habitats within the territory}

We found a clear diving selection for aquatic locations closer to the riverbank but found no clear diving selection as a function of distance from lodge, distance from territory border, or water depth (Table 4, Fig. 5a, Additional file 1 ). Diving selection probability varied as a function of sediment type. Locations having either mud, sand, or rock sediment were less selected than locations with clay sediment (Table 4, Fig. 5b). Furthermore, diving selection probability increased when several of either quillwort, shoreweed, and stonewort were present, but we found no effect of vegetation cover, overall species richness, or vegetation cover of the focal species on the diving selection probability (Table 4, Fig. 5c, Additional file 1).

Individual diving selection coefficients varied among individuals and territories. Individuals exploiting larger home ranges (i.e. 95\% AKDE) had a weaker selection for

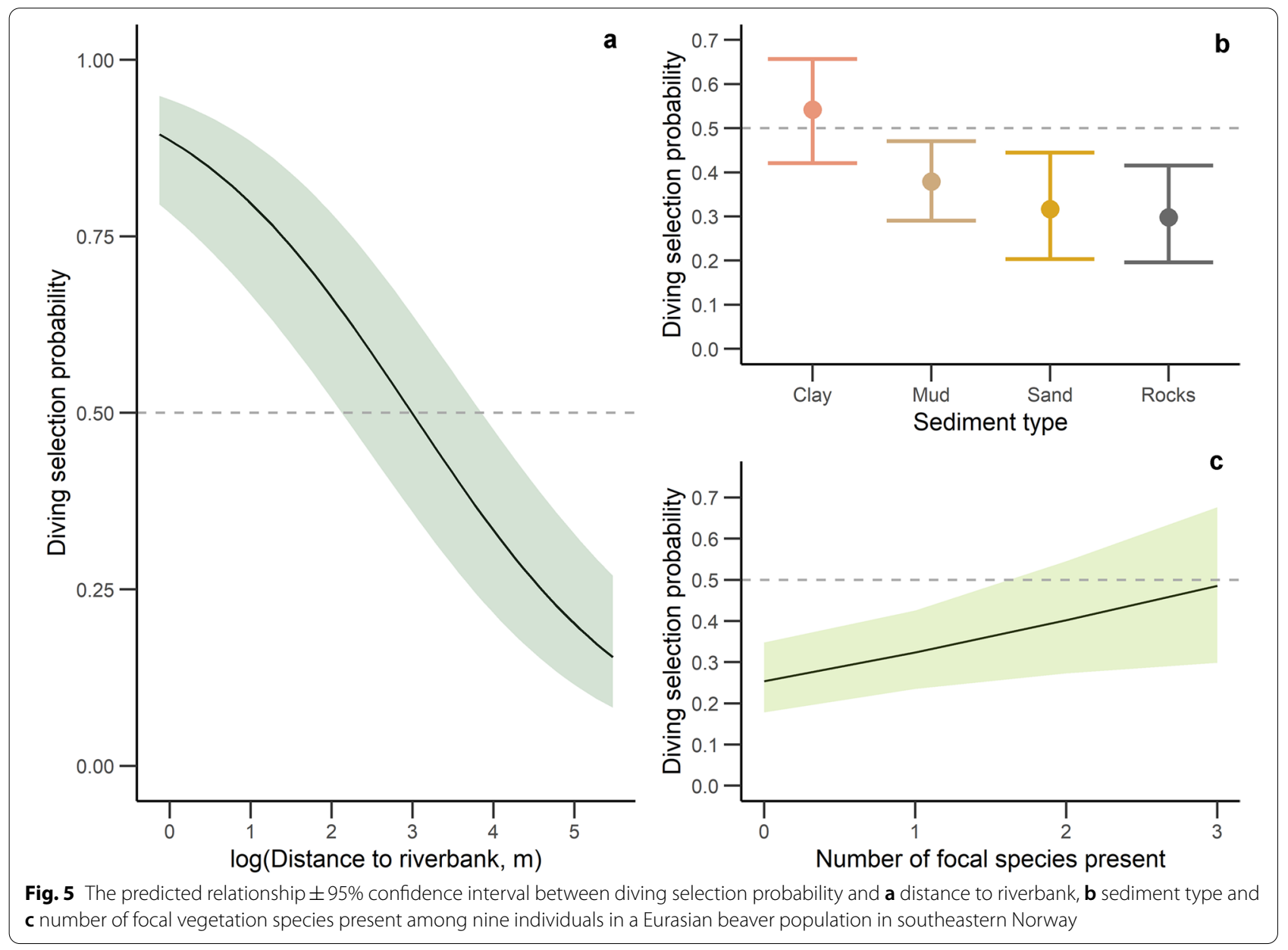


diving locations closer to the riverbank than individuals with smaller home ranges (Table 5, Fig. 6a). We found no clear context dependent effects on selection coefficients for the various sediment types (Additional file 1). Social rank had an effect on diving selection for number of focal species present which were stronger among subordinate

Table 5 Effect size $(\beta)$, standard error (SE), lower (LCI) and upper (UCI) 95\% confidence interval of explanatory variables for the analysis of individual selection coefficient for distance to riverbank and number of focal species present among nine individuals in a Eurasian beaver population in southeastern Norway

\begin{tabular}{|c|c|c|c|c|}
\hline Variable & Estimate $\beta$ & SE & LCl & $\mathrm{UCl}$ \\
\hline \multicolumn{5}{|c|}{ Selection for distance to riverbank } \\
\hline Intercept & -0.465 & 0.169 & -0.864 & -0.067 \\
\hline Log (home range) & -0.420 & 0.142 & -0.757 & -0.084 \\
\hline \multicolumn{5}{|c|}{$R^{2}: 0.56 \quad R_{\text {adjusted }}^{2} 0.49$} \\
\hline \multicolumn{5}{|c|}{ Selection for number of focal species present } \\
\hline Intercept & 0.175 & 0.131 & -0.135 & 0.485 \\
\hline Social rank subordinate & 0.922 & 0.228 & 0.384 & 1.460 \\
\hline$R^{2}: 0.70 \quad R_{\text {adjusted }}^{2}$ & & & & \\
\hline
\end{tabular}

Effects were modelled using a GLM with gaussian distribution. Analyses were weighed by number of diving sites for each individual. Informative parameters are given in bold

Reference level for social rank $=$ Dominant individuals than dominant individuals (Table 5, Fig. 6b). We found no conditional effects of other variables on the selection coefficients (Additional file 1).

We found that diving locations further from the riverbank had a deeper water depth and higher vegetation cover of focal species compared to diving locations closer to the riverbank (Table 6, Fig. 7a, b). Diving locations located further from the beaver lodge had a higher vegetation cover than diving locations closer to the beaver lodge (Table 6, Fig. 7c). Diving distance to the beaver lodge also increased with increasing tail fat index and decreased during the night and during the spring/early summer (Table 6, Fig. $7 \mathrm{~d}-\mathrm{f}$ ). Focusing on dives within $150 \mathrm{~m}$ of the beaver lodge, we found a difference among sediment types with dives located on clay and mud sediment being closer to the lodge than dives located on sand and rock (Table 6, Fig. 8).

\section{Discussion}

We provide new knowledge on aquatic habitat use in a semi-aquatic mammal, the Eurasian beaver, by examining finely resolved information on beaver movement and diving in relation to fine-scaled qualitative assessments of aquatic habitat characteristics within beaver territories. We observed clear spatiotemporal variations in hourly diving probability but found no differences among individuals or territories. Beavers selected for both spatial,

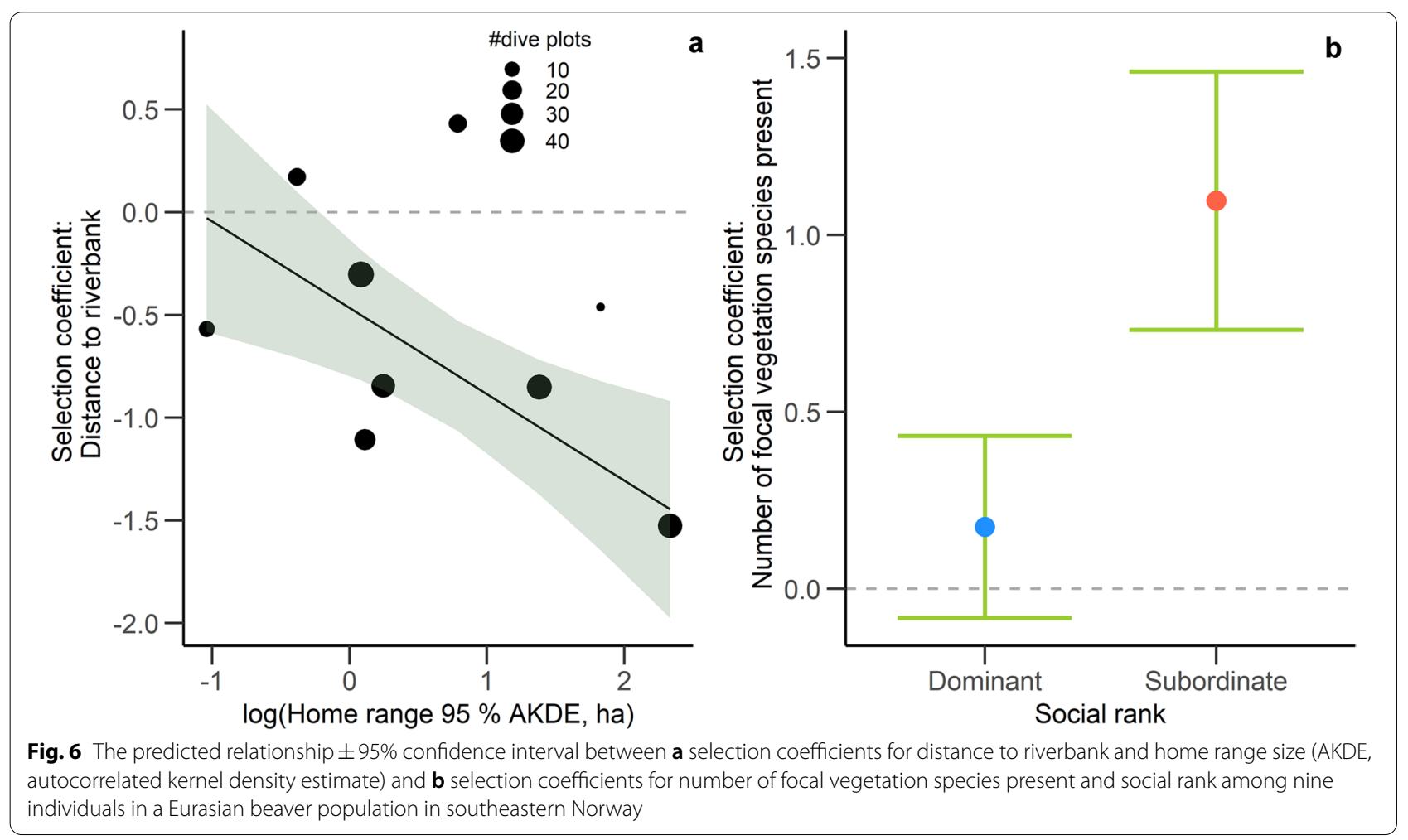


Table 6 Effect size $(\beta)$, standard error (SE), lower (LCI) and upper (UCI) $95 \%$ confidence interval of explanatory variables for the analyses of distance to riverbank and distance to beaver lodge among dives of nine individuals in a Eurasian beaver population in southeastern Norway

\begin{tabular}{|c|c|c|c|c|}
\hline Variable & Estimate $\beta$ & SE & $\mathrm{LCl}$ & UCI \\
\hline \multicolumn{5}{|l|}{ Distance to riverbank } \\
\hline Intercept & 2.226 & 0.071 & 2.087 & 2.365 \\
\hline Log (water depth) & 0.603 & 0.053 & 0.499 & 0.708 \\
\hline $\begin{array}{l}\text { Vegetation cover of } \\
\text { focal species }\end{array}$ & 0.010 & 0.003 & 0.005 & 0.015 \\
\hline Marginal $R^{2}: 0.35$ & \multicolumn{4}{|c|}{ Conditional $\boldsymbol{R}^{2}: 0.35$} \\
\hline \multicolumn{5}{|c|}{ Distance to beaver lodge } \\
\hline Intercept & 5.801 & 0.410 & -0.375 & 11.976 \\
\hline Vegetation cover & 0.006 & 0.002 & 0.002 & 0.009 \\
\hline Hour & -0.071 & 0.023 & -0.116 & -0.025 \\
\hline Julian day & -0.019 & 0.003 & -0.025 & -0.012 \\
\hline Tail fat index & 1.059 & 0.023 & 0.635 & 1.483 \\
\hline Marginal $R^{2}: 0.18$ & \multicolumn{4}{|c|}{ Conditional $R^{2}: 0.19$} \\
\hline \multicolumn{5}{|c|}{ Distance to beaver lodge (dives within $150 \mathrm{~m}$ ) } \\
\hline Intercept & 4.227 & 0.091 & 4.049 & 4.404 \\
\hline Sediment $_{\text {Clay }}$ & -0.098 & 0.152 & -0.395 & 0.199 \\
\hline Sediment $_{\text {Sand }}$ & 0.670 & 0.240 & 0.201 & 1.140 \\
\hline Sediment $t_{\text {Rocks }}$ & 0.309 & 0.147 & 0.021 & 0.597 \\
\hline Marginal $R^{2}: 0.25$ & \multicolumn{4}{|c|}{ Conditional $R^{2}: 0.25$} \\
\hline
\end{tabular}

Effects were modelled using a GLMMs with gaussian distribution. Beaver ID was included as random effect. Informative parameters are given in bold

Reference level for sediment $=$ Mud

physical and vegetation characteristics in their diving locations, highlighting the degree of choice they exercise for foraging behaviour although selection strength varied between individuals. Furthermore, spatial variations among dives indicate the energetic variability in aquatic habitat use. Often studies in freshwater-inhabiting semiaquatic mammals focus on the use of terrestrial habitat components, but we show how components of aquatic habitats similarly may be an important resource which can potentially have considerable fitness consequences for a semi-aquatic mammal like the beaver.

\section{Diving patterns}

The majority of our identified diving events were short, which matches previous findings for beavers [99, 101] and other semi-aquatic mammals [127-129]. Beavers have previously been reported to spend less than $3 \%$ of their nightly activity budget on diving activities which corresponds well with their role as generalist herbivores that do not rely solely on aquatic foraging [99]. Similar diving patterns have been found among semi-aquatic generalist carnivores and may relate to semi-aquatic animals being less specialized for the aquatic environment
[101, 129-131]. Beavers may preferably dive to bring large quantities of vegetation to the surface rather than consuming small amounts of vegetation underwater, saving energy by not diving repeatedly to exploit resources at depth, thereby also minimizing heat loss [132, 133]. In fact, an extensive study on diving in beavers by Graf et al. [99] found that animals had high dynamic body acceleration (DBA) (a good proxy for movement-based energy expenditure [134]) for the descent, indicating work done against appreciable buoyancy, as has been noted for many birds with their air-filled plumage [133]. Curiously though, in stark contrast to birds, which use this buoyancy for passive ascents [135], beavers also had high DBA values during their return to the surface, which was suggested to be due to animals having to transport vegetation from the bottom to the surface for consumption [99]. Similar behaviour is commonly observed in water birds such as Eurasian coots (Fulica atra) when foraging on aquatic vegetation $[136,137]$, but also in semi-aquatic carnivores such as American mink (Neovison vison) that occasionally consume aquatic food items at the surface or on the riverbank $[128,138]$. Critically, this behaviour is most advantageous when large amounts of food can be brought to the surface during one dive, which can then be consumed at leisure without the need for multiple, energetically onerous dives in repetitive feeding bouts such as those performed by carnivorous species [138, 139].

We found a decreased hourly diving probability in the early morning which is contrary to the findings of Graf et al. [99], although they had appreciable variation. Other studies have found a peak in general activity (measured via overall body dynamic acceleration) in the middle of the beavers' principal activity period, suggesting increased activity in the middle of the night [48]. Diving generally has a high overall body dynamic acceleration compared to other behavioural activities and therefore a higher movement-based energy cost [47, 134]. Diving patterns in beavers may be implicitly represented by this general activity pattern, peaking in the middle of the principal activity period, as aquatic habitat use may be costly for a semi-aquatic mammal [101, 140]. Similar diving patterns peaking in the middle of the activity period have been found in other semi-aquatic mammals, such as American mink, that perform temporal niche shifts to avoid interspecific aggression from competitors [128, 141].

Diving patterns may be structured according to the activity peaks of potential terrestrial predators [142]. When beavers bring aquatic resources onto the riverbank to be handled, their risk of predation increases [93, 95]. Beavers are at a particular risk when on land because of their poor eyesight under low light conditions (i.e. they lack tapetum lucidum) [143] and dependence on 

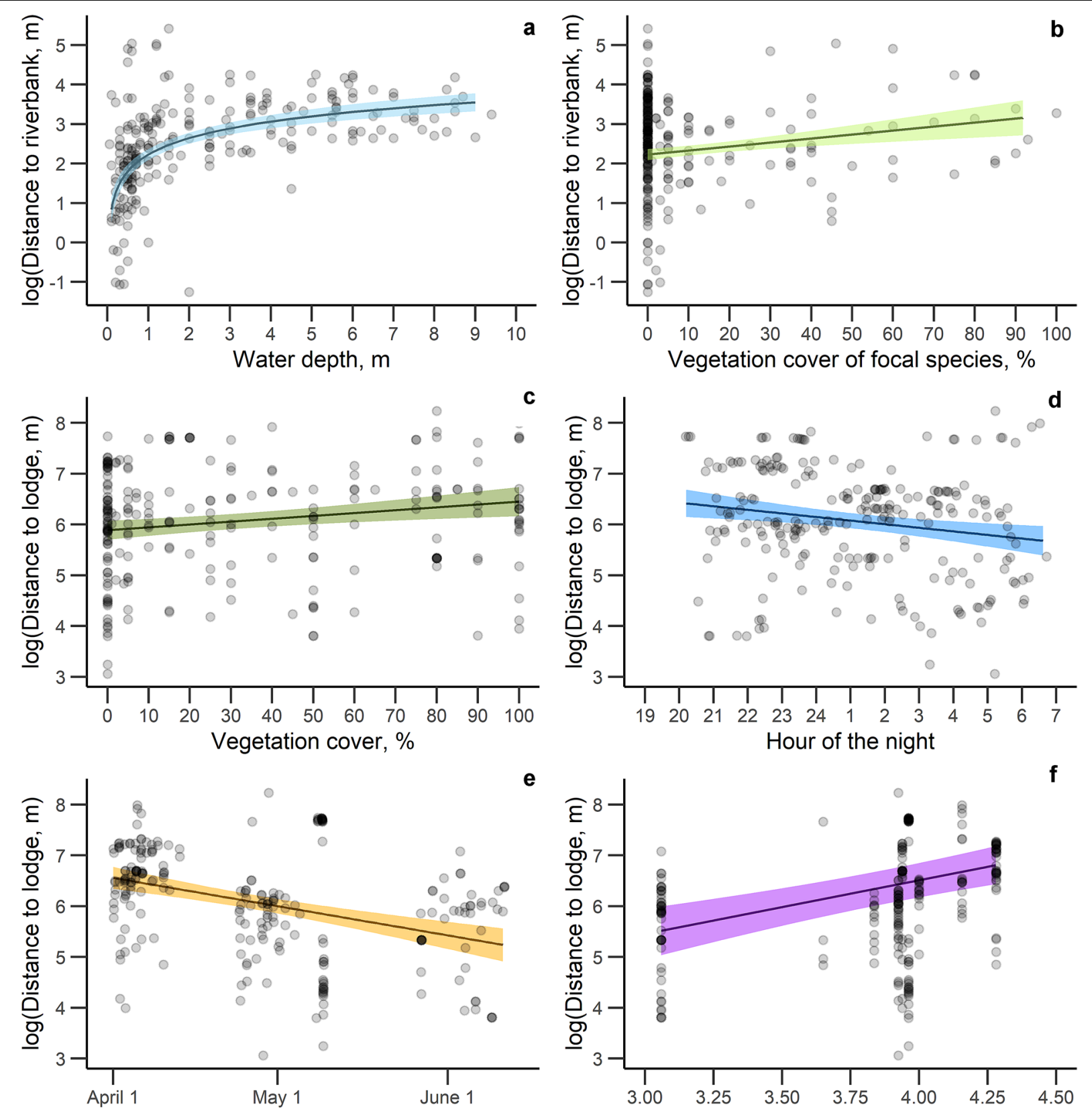

Date

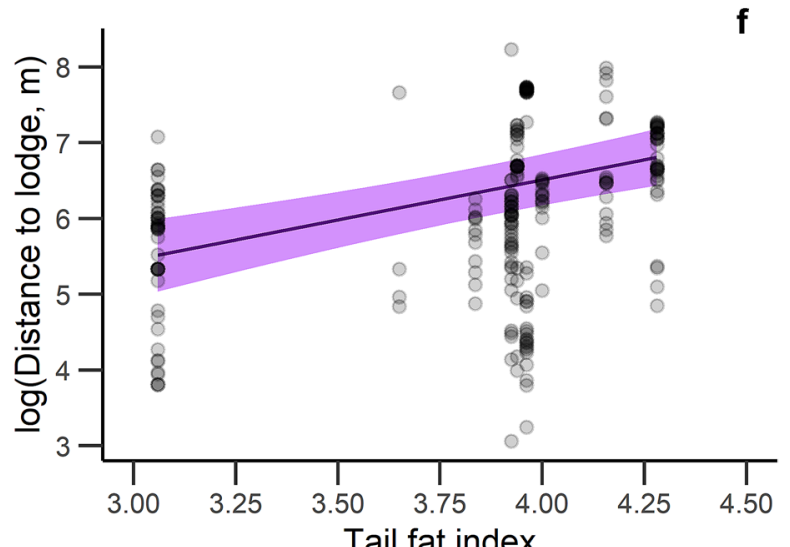

Fig. 7 The predicted relationship $\pm 95 \%$ confidence interval between distance to riverbank and beaver lodge and $\mathbf{a}$ water depth, $\mathbf{b}$ vegetation cover of focal species, $\mathbf{c}$ vegetation cover, $\mathbf{d}$ hour of the night, $\mathbf{e}$ Julian day, and $\mathbf{f}$ tail fat index among dives of nine individuals in a Eurasian beaver population in southeastern Norway. Points represent actual distances

olfaction to detect potential risks [144]. Consequently, they may not detect potential predators, such as wolves (Canis lupus) and Eurasian lynx (Lynx lynx) that have advanced night vision $[145,146]$, before being detected themselves. However, wolves have been observed to predate more at dawn, dusk, and during moonlit nights [142], which could increase the benefits of being most active (including diving) in the middle of the night when it is darkest. In North America, beavers make up a large proportion of wolf diet, especially during summer when wolves have been observed to ambush beavers at frequently used locations [95]. Natural predators are absent in our study area, but behavioural activities are known to be influenced by historical threats [84, 147]. In addition, 


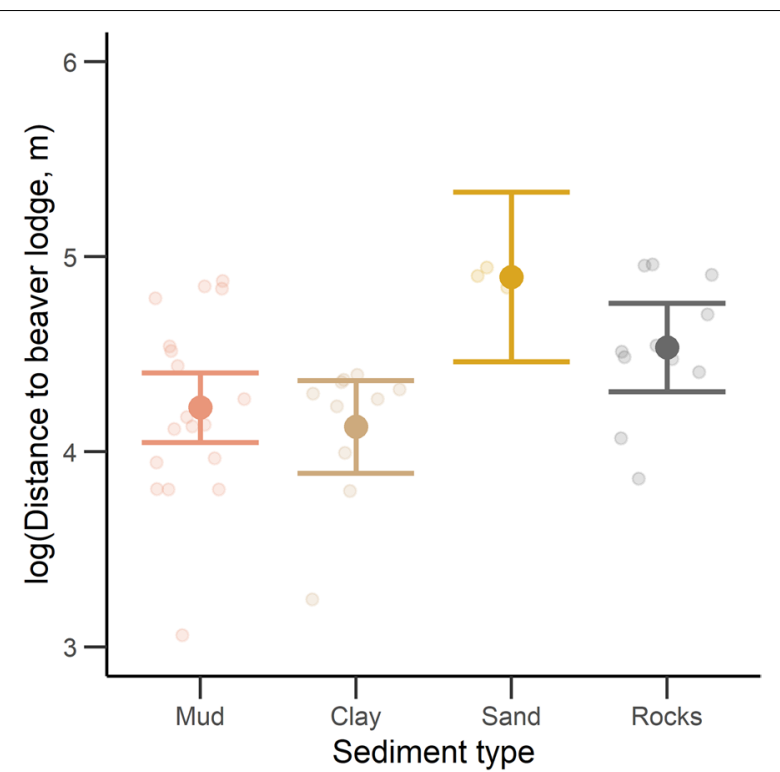

Fig. 8 The predicted relationship $\pm 95 \%$ confidence interval between distance to beaver lodge and sediment type among dives within $150 \mathrm{~m}$ of the beaver lodge of nine individuals in a Eurasian beaver population in southeastern Norway. Points represent actual distances

human activities both on land and on water, which are naturally reduced at night, may also influence the activity levels of beavers [147]. Consequently, diving for food resources at dusk and dawn may be perceived to be too risky for beavers.

Diving is presumably not just shaped by risks, but also allows the animals to have access to important aquatic resources [4, 81]. Hourly diving probability decreased with increasing distance from the territory borders which may indicate a possible depletion of aquatic resources near beaver lodges that are often located in central parts of the territory [cf. 148,149]. Although this may be expected to be related to territory size [33], we did not find this, possibly because our sample size was too small. Diving near the borders may also relate to territorial defence activities, which may help reduce aggressive territorial encounters when territorial intruders swim away unseen $[89,150,151]$. However, we were unable to quantify territorial behaviour.

\section{Diving selection}

We found a high selection for diving closer to the riverbank. Similar short and shallow dives have been found in other studies of semi-aquatic mammals which probably reflect the energetic constraints of bringing food resources to the riverbank for consumption and a preference for travelling along the riverbank [86, 99, 127, 128]. Association with a riverbank can, in some senses, be treated as a central place [152], which makes clear the energetic costs of leaving the central place to acquire food. In that sense, the decreasing tendency to dive with increasing distance from the riverbank ties in with optimal foraging theory, which has animals maximizing reward and minimizing transit time and energy [153, 154]. Distance to the riverbank may also reflect decreasing aquatic foraging options in terms of decreased macrophyte growth which is highly dependent on water depth and light penetration [114]. But short shallow dives may also be preferred as they are energetically cheaper for semi-aquatic animals like beavers that have high buoyancy [140]. In general, diving locations in semi-aquatic carnivores have been shown to follow distributions of aquatic food resources [127, 155]. We noted that selection for diving locations near the riverbank was statistically stronger among individuals that exploited a larger home range: individuals that exploit a larger home range may have a greater need to stay closer to the riverbank due to higher territory patrolling efforts whereas individuals exploiting smaller home ranges may be able to forage further away from the riverbank [86]. Individuals using larger areas or inhabiting larger territories may also have reduced resource depletion so that, conversely, beavers restricted to smaller areas may be forced to exploit foraging areas further away from the riverbank $[33,156]$. Larger home ranges may also have a greater area of shallow water, which, depending on the time spent diving, can be energetically easier to exploit for a semi-aquatic animal [140]. Conversely, individuals with smaller home ranges may have to exploit all habitats to fulfil their energetic requirements [33]. We saw that water depth at the diving locations generally increased with increasing distance from the riverbank, which presumably represent higher energetic costs of diving away from the riverbank, but dives at longer distances from the riverbank also had higher amounts of quillwort, shoreweed, and stonewort present, possibly due to the Ashmole's halo effect [148, 149] operating on animals preferentially associated with the shoreline. This indicates the interplay of depth and distance energetics in a semi-aquatic animal, which have to be balanced with the calorific value of the food plants and their location [132, 133, 140].

Beavers had a higher selection for diving at locations with clay sediment, which may be an important building material for lodges and dams [96], although dams are not present in our study site, and beavers may additionally make use of burrows dug into the riverbank whereby the clay sediment aids in enhancing the structural integrity of those burrows $[157,158]$. Lodges and dams are mostly repaired in the autumn $[159,160]$, but may be repaired after flooding events too [161]. Mud is also widely used for beaver constructions [97], although mud substrates, 
despite being highly abundant in the study area, seemed not to be selected. Beavers continuously need to apply fresh mud and other fine debris to seal their constructions as it is continuously washed away [96, 97]. We found that dives on mud and clay sediment within $150 \mathrm{~m}$ of the beaver lodge were generally located closer to the beaver lodges than dives located on sand and rock sediment which, we believe, indicates the importance of fine sediment for building constructions. However, we cannot rule out that mud and clay sediment may contain advantageous foraging options, although our ordination did not show strong correlation between mud and clay sediment with aquatic species richness or vegetation cover.

We found a higher selection for diving locations with presence of species of quillwort, shoreweed, and stonewort, which may represent important food resources for the beaver. Other studies have similarly found a high preference for quillwort in the early summer [73], and algae like stonewort may be selected for its protein content and other nutrients [65]. Although beavers mainly forage on woody vegetation, aquatic vegetation seems to be seasonally important, with studies additionally reporting beavers foraging on, among others, water lilies (Nymphaea spp.), pondweed (Potamogeton spp.), water horsetail (Equisetum spp.), waterweed (Elodea spp.), and water lobelia (Lobelia dortmanna) [64-66, 68, 69, $71,98]$. Incorporating aquatic vegetation into a varied diet could be a strategy to minimize risk of nutrient deficiency [162], which may be seasonally beneficial to some individuals (e.g. females during lactation when energetic requirements increase) $[163,164]$. However, we did not find any selection differences between males and females which may be because of our limited number of individuals. Other studies on semi-aquatic mammals show how males and females in two species of shrew (Neomys fodiens and Sorex coronatus) use separate foraging habitats during the breeding season [165]. Males and females in our population have been shown to differ seasonally in aquatic foraging with peaks in the spring and late summer for females, whereas males only foraged on aquatic vegetation in the spring [166]. We found that selection for the focal plant species were statistically stronger among subordinate individuals, which may be linked to their higher energetic requirements resulting from their activities related to attempts to become dominant in a territory [57] (e.g. performing more extra territorial movements [15]). A higher use of aquatic vegetation may also be a risk-avoiding strategy, minimizing predation risk on land $[92,95]$. In other studies, adult beavers have been found to forage less on aquatic vegetation than subadult individuals (i.e. 2-year-old) [65] which may be less risk-willing as they potentially face higher fitness costs in terms of future reproductive success [167] and therefore adjust their foraging strategy accordingly $[4,168]$. Similarly, we found that beavers with lower tail fat index tended to dive closer to their lodge, which may be a consequence of territorial constraints as individuals with higher body condition may be better able to cope with the increased cost of patrolling and protecting territory borders $[18,86]$. Diving locations located further from the beaver lodge also had higher amounts of vegetation cover which indicate the energetic trade-offs between costs and benefits that a central place foraging individual experiences $[4,169]$. Diving distance to the lodge decreased through the night which may indicate a functional change in the purpose of the dive. As dives further from the lodge occurred at locations with more aquatic vegetation, these dives may be intended for foraging whereas dives later in the night may be used for building activities. We also saw that diving distance to the lodge decreased from early spring to summer, which may relate to increased parenting activities that require the beaver to stay closer to the lodge when the kits are born in mid-May [58]. Diving for food resources may be perceived as less risk-taking than going on land [87] and could be preferred by parenting individuals to ensure the growth and survival of their offspring [170].

\section{Methodological limitations}

Using dead-reckoning together with an accelerationbased behavioural classification model to identify the temporal and spatial distribution of clear diving events, we identified considerably fewer diving events than a previous study in beavers that identified typically 40 dives per night [99]. This may be related to seasonal variations as we only tracked beavers from April to June, whereas Graf et al. [99] also included observations from the autumn (September to October) where diving conditions may be more favourable, because of increased water temperature and life history patterns $[15,57,99]$. But dives may also be masked by our method. Despite a high classification accuracy of diving events from the model by Graf et al. [47], some events may not be identified because some behavioural activities, including behaviours not described by the model, can have similar patterns and mask each other [47]. Therefore, it is important to clearly define each behavioural activity in an acceleration-based classification model, but also to include enough variations of each activity from several individuals to improve the precision of the model. Different diving styles may be misclassified as other behavioural categories if the behavioural classification model is not trained on several variations of each behavioural category but only includes typical acceleration patterns for each behavioural category. For example, the ecological difference between a 'dive' and an 'almost dive' may be minimal when a 
beaver can access aquatic resources by just sticking its head underwater, but they may fall within two different behavioural categories because of variable acceleration patterns. The acceleration can also be affected by external environmental forces such as wave actions [134], which can be corrected by incorporating magnetism in the classification [50]. We also only gathered acceleration in $10 \mathrm{~s}$ bursts for the classification model, which may mask some of the diving events of shorter duration. A more detailed inspection of the fine-scale acceleration and body postures may improve the classification and provide more information on the actual behavioural activity $[171,172]$. Placing the behavioural activities into a larger context (i.e. what the animal did before and after an activity) would furthermore help understand the ecological significance of each activity. In addition, the ability of dead-reckoning procedures is spatially limited by the precision of the GPS positions that are used to ground-truth the deadreckoned movement tracks $[49,51]$, which means that we will have introduced some spatial error in the locations of the diving events $[112,113]$. However, this potential error will be consistent along the tracking period making it less likely to bias our results. The high classification accuracy of the model together with the filtering of less likely diving locations (e.g. on land or not in combination with swimming) improve our confidence in our ability to classify relevant diving locations in our beaver population.

\section{Conclusion}

By coupling fine-scaled information on individual beavers' movement and diving with comprehensive qualitative assessments of aquatic habitat characteristics within beaver territories, we provided new knowledge on the aquatic habitat use by a freshwater semi-aquatic mammal. We showed how energetic constraints may shape beavers' spatial use of the aquatic environment, and how aquatic habitats may have great importance for both foraging, building materials and safety, even in absence of natural predators. However, future studies should investigate the importance of aquatic habitat use relative to terrestrial habitat use. Several groups of individuals experiencing various ecological conditions may benefit greatly from the use of aquatic resources, consequently affecting their body condition, reproduction, and survival [57, 90], which should be investigated further in future studies including more individuals and populations.

\section{Supplementary Information}

The online version contains supplementary material available at https://doi. org/10.1186/s40317-021-00259-7.

Additional file 1: S1. The model selection results for the best candidate models investigating the number of dives per night among nine beavers in a Eurasian beaver population in south-eastern Norway. S2. The model selection results for the best candidate models investigating the diving probability among nine beavers in a Eurasian beaver population in south-eastern Norway. S3. List of aquatic species abundance in Saua river in south-eastern Norway. $\mathbf{S 4}$. The model selection results for the best candidate models investigating the diving habitat selection among nine beavers in a Eurasian beaver population in south-eastern Norway. S5. The model selection results for the best candidate models investigating the individual context-dependent diving selection for distance to riverbank among nine beavers in a Eurasian beaver population in south-eastern Norway. S6. The model selection results for the best candidate models investigating the individual context-dependent diving selection for clay sediment among nine beavers in a Eurasian beaver population in southeastern Norway. S7. The model selection results for the best candidate models investigating the individual context-dependent diving selection for mud sediment among nine beavers in a Eurasian beaver population in south-eastern Norway. S8. The model selection results for the best candidate models investigating the individual context-dependent diving selection for sand sediment among nine beavers in a Eurasian beaver population in south-eastern Norway. S9. The model selection results for the best candidate models investigating the individual context-dependent diving selection for rock sediment among nine beavers in a Eurasian beaver population in south-eastern Norway. S10. The model selection results for the best candidate models investigating the individual contextdependent diving selection for species richness of focal species among nine beavers in a Eurasian beaver population in south-eastern Norway. S11. The model selection results for the best candidate models investigating the diving distance to riverbank among nine beavers in a Eurasian beaver population in south-eastern Norway. S12. The model selection results for the best candidate models investigating the diving distance to beaver lodge among nine beavers in a Eurasian beaver population in south-eastern Norway. S13. The model selection results for the best candidate models investigating the diving distance to beaver lodge among dives within $150 \mathrm{~m}$ of the lodge of nine beavers in a Eurasian beaver population in south-eastern Norway.

\section{Acknowledgements}

This study was conducted under the Norwegian Beaver Project at University of South-Eastern Norway. We thank every member within the NBP who contributed to the field work and especially H. K. Lodberg-Holm for also participating in early discussions of the project. We thank C. Catoni from Techno Smart and M. Holton from Wildbyte technologies for technical support.

\section{Authors' contributions}

FR founded the NBP and RMM obtained additional supporting funding for this subproject. RMM, SR, MEH, and FR developed the study design. MEH led the field work of the study with support from RMM, SR and FR. RMM performed the statistical analyses with support from SR and MEH. RMM wrote the manuscript with support from SR, RPW and FR. All authors read and approved the final manuscript.

\section{Funding}

This study was funded by the University of South-Eastern Norway and partially supported by the Royal Norwegian Society of Sciences and Letters.

\section{Availability of data and materials}

The datasets used and analysed during the current study are available from the corresponding author on reasonable request.

\section{Declarations}

\section{Ethics approval and consent to participate}

All capture and handling procedures were approved by the Norwegian Experimental Animal Board (FOTS ID15947) and by the Norwegian Directorate for Nature Management (2014/14415). Our study met the ASAB/ABS Guidelines for the treatment of animals in behavioural research and teaching [173]. No individuals were injured during capture and handling, and they were all successfully released. All methods were performed in accordance 
with the relevant guidelines and regulations [174]. No short-term effects have been observed on the movement after tagging [48]. Body mass of dominant individuals have been observed to decrease with number of capture and handling events, but no statistically clear effects have been observed on survival or other body condition indices [57]. Number of capture and handling events was also observed to affect reproduction, but the population seemed habituated to repeated capture and handling in the long-term [57]. To minimize potential risks, the NBP prioritized capture and handling individuals that were necessary for the monitoring and experiments with clear objectives.

\section{Consent for publication}

Not applicable.

\section{Competing interests}

The authors declare that they have no competing interests.

\section{Author details}

${ }^{1}$ Faculty of Technology, Natural Sciences, and Maritime Sciences, Department of Natural Sciences and Environmental Health, University of South-Eastern Norway, Bø i Telemark, Norway. ${ }^{2}$ Biosciences, College of Science, Swansea University, Swansea, UK.

Received: 15 June 2021 Accepted: 11 August 2021

Published online: 18 August 2021

\section{References}

1. Wilson RP, Quintana F, Hobson VJ. Construction of energy landscapes can clarify the movement and distribution of foraging animals. Philos Trans R Soc B Biol Sci. 2012;279(1730):975-80.

2. Wall J, Douglas-Hamilton I, Vollrath F. Elephants avoid costly mountaineering. Curr Biol. 2006;16(14):R527-9.

3. Wilson RP, Griffiths IW, Legg PA, Friswell MI, Bidder OR, Halsey LG, Lambertucci SA, Shepard EL. Turn costs change the value of animal search paths. Ecol Lett. 2013;16(9):1145-50.

4. Gallagher AJ, Creel S, Wilson RP, Cooke SJ. Energy landscapes and the landscape of fear. Trends Ecol Evol. 2017;32(2):88-96.

5. Halsey LG. Terrestrial movement energetics: current knowledge and its application to the optimising animal. J Exp Biol. 2016;219(Pt 10):1424-31.

6. Shepard EL, Wilson RP, Rees WG, Grundy E, Lambertucci SA, Vosper SB. Energy landscapes shape animal movement ecology. Am Nat. 2013;182(3):298-312.

7. Laundré JW, Hernández L, Ripple WJ. The landscape of fear: ecological implications of being afraid. Open Ecol J. 2010;3:1-7.

8. Bleicher SS. The landscape of fear conceptual framework: definition and review of current applications and misuses. PeerJ. 2017;5:e3772.

9. Gaynor KM, Brown JS, Middleton AD, Power ME, Brashares JS. Landscapes of fear: spatial patterns of risk perception and response. Trends Ecol Evol. 2019;34:355-68.

10. Dickie M, McNay SR, Sutherland GD, Cody M, Avgar T. Corridors or risk? Movement along, and use of, linear features varies predictably among large mammal predator and prey species. J Anim Ecol. 2020;89(2):623-34.

11. Fortin D, Beyer HL, Boyce MS, Smith DW, Duchesne T, Mao JS. Wolves influence elk movements: behavior shapes a trophic cascade in Yellowstone National Park. Ecology. 2005;86(5):1320-30.

12. Shaw AK, Couzin ID. Migration or residency? The evolution of movement behavior and information usage in seasonal environments. Am Nat. 2013:181(1):114-24.

13. Ariano-Sánchez D, Mortensen RM, Reinhardt S, Rosell F. Escaping drought: seasonality effects on home range, movement patterns and habitat selection of the Guatemalan Beaded Lizard. Glob Ecol Conserv. 2020;23:e01178.

14. Marshall BM, Crane M, Silva I, Strine CT, Jones MD, Hodges CW, Suwanwaree P, Artchawakom T, Waengsothorn S, Goode M. No room to roam: King Cobras reduce movement in agriculture. Mov Ecol. 2020;8(1):1-14.

15. Mayer M, Zedrosser A, Rosell F. Extra-territorial movements differ between territory holders and subordinates in a large, monogamous rodent. Sci Rep. 2017;7(1):15261.
16. Morales JM, Moorcroft PR, Matthiopoulos J, Frair JL, Kie JG, Powell RA, Merrill EH, Haydon DT. Building the bridge between animal movement and population dynamics. Philos Trans R Soc B Biol Sci. 2010;365(1550):2289-301.

17. Larsen KW, Boutin S. Movements, survival, and settlement of red squirrel (Tamiasciurus hudsonicus) offspring. Ecology. 1994;75(1):214-23.

18. Amsler SJ. Energetic costs of territorial boundary patrols by wild Chimpanzees. Am J Primatol. 2010;72(2):93-103.

19. Shier DM, Swaisgood RR. Fitness costs of neighborhood disruption in translocations of a solitary mammal. Conserv Biol. 2012;26(1):116-23.

20. Nathan R, Getz WM, Revilla E, Holyoak M, Kadmon R, Saltz D, Smouse PE. A movement ecology paradigm for unifying organismal movement research. Proc Natl Acad Sci USA. 2008;105(49):19052-9.

21. Wheatley R, Buettel JC, Brook BW, Johnson CN, Wilson RP. Accidents alter animal fitness landscapes. Ecol Lett. 2021;24:920-34.

22. Maher CR, Lott DF. Definitions of territoriality used in the study of variation in vertebrate spacing systems. Anim Behav. 1995;49(6):1581-97.

23. Dunham ML, Warner RR, Lawson JW. The dynamics of territory acquisition: a model of two coexisting strategies. Theor Popul Biol. 1995:47(3):347-64.

24. Orians GH, Wittenberger JF. Spatial and temporal scales in habitat selection. Am Nat. 1991;137:S29-49.

25. Mysterud A, Ims RA. Functional responses in habitat use: availability influences relative use in trade-off situations. Ecology. 1998;79(4):1435-41.

26. Creel S, Winnie J, Maxwell B, Hamlin K, Creel M. Elk alter habitat selection as an antipredator response to wolves. Ecology. 2005;86(12):3387-97.

27. Abrams PA. Adaptive change in the resource-exploitation traits of a generalist consumer: the evolution and coexistence of generalists and specialists. Evolution. 2006;60(3):427-39.

28. Mangel $\mathrm{M}$, Clark CW. Towards a unifield foraging theory. Ecology. 1986;67(5):1127-38.

29. van Beest FM, Uzal A, Vander Wal E, Laforge MP, Contasti AL, Colville $D, M c L o u g h l i n$ PD. Increasing density leads to generalization in both coarse-grained habitat selection and fine-grained resource selection in a large mammal. J Anim Ecol. 2014;83(1):147-56.

30. Fortin D, Morris DW, McLoughlin PD. Habitat selection and the evolution of specialists in heterogeneous environments. Isr J Ecol Evol. 2008:54(3-4):311-28.

31. Veron G, Patterson BD, Reeves R. Global diversity of mammals (Mammalia) in freshwater. Freshwater Animal Diversity Assessment. Berlin: Springer; 2007. p. 607-17.

32. Dunstone N. Adaptations to the semi-aquatic habit and habitat. Behav Ecol Riparian Mamm. 1998;71:1-16.

33. Campbell RD, Rosell F, Nolet BA, Dijkstra VAA. Territory and group sizes in Eurasian beavers (Castor fiber): echoes of settlement and reproduction? Behav Ecol Sociobiol. 2005;58(6):597-607.

34. Johnson $\mathrm{DH}$. The comparison of usage and availability measurements for evaluating resource preference. Ecology. 1980;61 (1):65-71.

35. Manly B, McDonald L, Thomas DL, McDonald TL, Erickson WP. Resource selection by animals: statistical design and analysis for field studies. New York: Springer Science \& Business Media; 2007.

36. McLoughlin PD, Coulson T, Clutton-Brock T. Cross-generational effects of habitat and density on life history in red deer. Ecology. 2008:89(12):3317-26

37. McLoughlin PD, Morris DW, Fortin D, Vander Wal E, Contasti AL. Considering ecological dynamics in resource selection functions. J Anim Ecol. 2010;79(1):4-12.

38. Steyaert SMJG, Zedrosser A, Rosell F. Socio-ecological features other than sex affect habitat selection in the socially obligate monogamous Eurasian beaver. Oecologia. 2015;179(4):1023-32.

39. Bleicher SS, Rosenzweig ML. Too much of a good thing? A landscapeof-fear analysis for collared peccaries (Pecari tajacu) reveals hikers act as a greater deterrent than thorny or bitter food. Can J Zool. 2018:96(4):317-24.

40. Hebblewhite M, Haydon DT. Distinguishing technology from biology: a critical review of the use of GPS telemetry data in ecology. Philos Trans R Soc B Biol Sci. 2010;365(1550):2303-12. 
41. Elliott KH. Measurement of flying and diving metabolic rate in wild animals: review and recommendations. Comp Biochem Physiol Part A. 2016;202:63-77.

42. Wilson ADM, Wikelski M, Wilson RP, Cooke SJ. Utility of biological sensor tags in animal conservation. Conserv Biol. 2015;29(4):1065-75.

43. Cagnacci F, Boitani L, Powell RA, Boyce MS. Animal ecology meets GPSbased radiotelemetry: a perfect storm of opportunities and challenges. Philos Trans R Soc B. 2010;365(1550):2157-62.

44. Williams HJ, Taylor LA, Benhamou S, Bijleveld Al, Clay TA, de Grissac S, Demsar U, English HM, Franconi N, Gomez-Laich A, Griffiths RC, Kay WP, Morales JM, Potts JR, Rogerson KF, Rutz C, Spelt A, Trevail AM, Wilson RP, Borger L. Optimizing the use of biologgers for movement ecology research. J Anim Ecol. 2019:89:186-206.

45. Hughey LF, Hein AM, Strandburg-Peshkin A, Jensen FH. Challenges and solutions for studying collective animal behaviour in the wild. Philos Trans R Soc B Biol Sci. 2018;373(1746):20170005.

46. Brown DD, Kays R, Wikelski M, Wilson R, Klimley AP. Observing the unwatchable through acceleration logging of animal behavior. Anim Biotelemetry. 2013;1(1):20.

47. Graf PM, Wilson RP, Qasem L, Hacklander K, Rosell F. The use of acceleration to code for animal behaviours; a case study in free-ranging Eurasian beavers Castor fiber. PLoS ONE. 2015;10(8):e0136751.

48. Graf PM, Hochreiter J, Hacklander K, Wilson RP, Rosell F. Short-term effects of tagging on activity and movement patterns of Eurasian beavers (Castor fiber). Eur J Wildl Res. 2016;62(6):725-36.

49. Bidder OR, Walker JS, Jones MW, Holton MD, Urge P, Scantlebury DM, Marks NJ, Magowan EA, Maguire IE, Wilson RP. Step by step: reconstruction of terrestrial animal movement paths by dead-reckoning. Mov Ecol. 2015;3(1):23.

50. Williams HJ, Holton MD, Shepard ELC, Largey N, Norman B, Ryan PG, Duriez O, Scantlebury M, Quintana F, Magowan EA, Marks NJ, Alagaili AN, Bennett NC, Wilson RP. Identification of animal movement patterns using tri-axial magnetometry. Mov Ecol. 2017;5:6.

51. Gunner R, Holton M, Scantlebury M, Lv S, English H, Williams H, Hopkins P, Quintana F, Gómez-Laich A, Börger L. Dead-reckoning animal movements in R-A reappraisal using Gundog.Tracks. Anim Biotelemetry. 2021;9:23

52. Wilson RP, Shepard ELC, Liebsch N. Prying into the intimate details of animal lives: use of a daily diary on animals. Endangered Species Res. 2008:4:123-37.

53. Wright BM, Ford JK, Ellis GM, Deecke VB, Shapiro AD, Battaile BC, Trites AW. Fine-scale foraging movements by fish-eating killer whales (Orcinus orca) relate to the vertical distributions and escape responses of salmonid prey (Oncorhynchus spp.). Mov Ecol. 2017;5(1):1-18.

54. Studd EK, Boudreau MR, Majchrzak YN, Menzies AK, Peers MJL, Seguin JL, Lavergne SG, Boonstra R, Murray DL, Boutin S, Humphries MM. Use of acceleration and acoustics to classify behavior, generate time budg ets, and evaluate responses to moonlight in free-ranging snowshoe hares. Front Ecol Evol. 2019;7:154.

55. Jeantet L, Planas-Bielsa V, Benhamou S, Geiger S, Martin J, Siegwalt F, Lelong P, Gresser J, Etienne D, Hiélard G. Behavioural inference from signal processing using animal-borne multi-sensor loggers: a novel solution to extend the knowledge of sea turtle ecology. R Soc Open Sci. 2020;7(5):200139.

56. Chimienti M, van Beest FM, Beumer LT, Desforges JP, Hansen LH, Stelvig M, Schmidt NM. Quantifying behavior and life-history events of an Arctic ungulate from year-long continuous accelerometer data. Ecosphere. 2021:12(6):e03565.

57. Mortensen RM, Rosell F. Long-term capture and handling effects on body condition, reproduction and survival in a semi-aquatic mammal. Sci Rep. 2020;10(1):1-16.

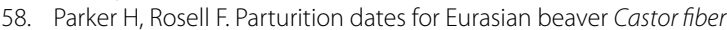
when should spring hunting cease? Wildl Biol. 2001;7(3):237-41.

59. Parker $\mathrm{H}$, Zedrosser A, Rosell F. Age-specific reproduction in relation to body size and condition in female Eurasian beavers. J Zool. 2017;302(4):236-43.

60. Sun L, Müller-Schwarze D, Schulte BA. Dispersal pattern and effective population size of the beaver. Can J Zool. 2000;78(3):393-8.

61. Gallant D, Bérubé $\mathrm{CH}$, Tremblay E, Vasseur L. An extensive study of the foraging ecology of beavers (Castor canadensis) in relation to habitat quality. Can J Zool. 2004;82(6):922-33.
62. Haarberg O, Rosell F. Selective foraging on woody plant species by the Eurasian beaver (Castor fiber) in Telemark, Norway. J Zool. 2006:270(2):201-8.

63. Fryxell JM, Doucet CM. Provisioning time and central-place foraging in beavers. Can J Zool. 1991;69(5):1308-13.

64. Milligan HE, Humphries MM. The importance of aquatic vegetation in beaver diets and the seasonal and habitat specificity of aquaticterrestrial ecosystem linkages in a subarctic environment. Oikos. 2010;119(12):1877-86.

65. Svendsen GE. Seasonal change in feeding patterns of beaver in southeastern Ohio. J Wildl Manag. 1980;44(1):285-90.

66. Doucet CM, Fryxell JM. The effect of nutritional quality on forage preference by beavers. Oikos. 1993:67:201-8.

67. Gerwing TG, Johnson CJ, Alström-Rapaport C. Factors influencing forage selection by the North American beaver (Castor canadensis). Mamm Biol. 2013;78(2):79-86.

68. Roberts TH, Arner DH. Food habits of beaver in east-central Mississippi. J Wildl Manag. 1984;48(4):1414-9.

69. Bełżecki G, Miltko R, Kowalik B, Demiaszkiewicz A, Lachowicz J, Giżejewski Z, Obidziński A, McEwan N. Seasonal variations of the digestive tract of the Eurasian beaver Castor fiber. Mamm Res. 2018;63(1):21-31.

70. Law A, Jones KC, Willby NJ. Medium vs. short-term effects of herbivory by Eurasian beaver on aquatic vegetation. Aquat Bot. 2014;116:27-34.

71. Law A, Bunnefeld N, Willby N. Beavers and lilies: selective herbivory and adaptive foraging behaviour. Freshw Biol. 2014;59(2):224-32.

72. Vorel A, Válková L, Hamšíková L, Maloň J, Korbelová J. Beaver foraging behaviour: seasonal foraging specialization by a choosy generalist herbivore. Behav Ecol Sociobiol. 2015;69(7):1221-35.

73. Simonsen TA. Beverens næringsøkologi i vest-agder, Meddelelser fra Statens viltundersøkelser, 2. serie, nr. 39; 1973.

74. Fraser D, Chavez E, Palohelmo J. Aquatic feeding by moose: selection of plant species and feeding areas in relation to plant chemical composition and characteristics of lakes. Can J Zool. 1984;62(1):80-7.

75. Bergman BG, Bump JK. Revisiting the role of aquatic plants in beaver habitat selection. Am Midl Nat. 2018;179(2):222-46.

76. Nolet BA, Van Der Veer P, Evers E, Ottenheim MM. A linear programming model of diet choice of free-living beavers. Netherlands J Zool. 1995;45(3-4):315-37.

77. Harrison P, Mann K. Detritus formation from eelgrass (Zostera marina L.): the relative effects of fragmentation, leaching, and decay. Limnol Oceanogr. 1975;20:924-34.

78. Haraguchi A. Seasonal changes in redox properties of peat, nutrition and phenology of Menyanthes trifoliata L. in a floating peat mat in Mizorogaike Pond, central Japan. Aquat Ecol. 2004;38(3):351-7.

79. Belovsky GE. Summer diet optimization by beaver. Am Midland Nat. 1984;111:209-22

80. Fryxell JM, Vamosi SM, Walton RA, Doucet CM. Retention time and the functional response of beavers. Oikos. 1994;71:207-14.

81. Gallant D, Leger L, Tremblay E, Berteaux D, Lecomte N, Vasseur L. Linking time budgets to habitat quality suggests that beavers (Castor canadensis) are energy maximizers. Can J Zool. 2016;94(10):671-6.

82. Rosell F, Bozser O, Collen P, Parker H. Ecological impact of beavers Castor fiber and Castor canadensis and their ability to modify ecosystems. Mamm Rev. 2005;35(3-4):248-76.

83. Basey JM, Jenkins SH. Influences of predation risk and energy maximization on food selection by beavers (Castor canadensis). Can J Zool. 1995;73(12):2197-208.

84. Rosell F, Sanda J. Potential risks of olfactory signaling: the effect of predators on scent marking by beavers. Behav Ecol. 2006;17(6):897-904

85. Krojerová-Prokešová J, Barančeková M, Hamšíková L, Vorel A. Feeding habits of reintroduced Eurasian beaver: spatial and seasonal variation in the use of food resources. J Zool. 2010;281(3):183-93.

86. Graf PM, Mayer M, Zedrosser A, Hacklander K, Rosell F. Territory size and age explain movement patterns in the Eurasian beaver. Mamm Biol. 2016:81(6):587-94.

87. Bartra Cabré L, Mayer M, Steyaert S, Rosell F. Beaver (Castor fiber) activity and spatial movement in response to light and weather conditions. Mamm Biol. 2020;100:1-11.

88. Sharpe F, Rosell F. Time budgets and sex differences in the Eurasian beaver. Anim Behav. 2003;66(6):1059-67. 
89. Mayer M, Frank SC, Zedrosser A, Rosell F. Causes and consequences of inverse density-dependent territorial behaviour and aggression in a monogamous mammal. J Anim Ecol. 2019;89(2):577-88.

90. Severud WJ, Windels SK, Belant JL, Bruggink JG. The role of forage availability on diet choice and body condition in American beavers (Castor canadensis). Mamm Biol. 2013;78(2):87-93.

91. Gable TD, Windels SK, Romanski MC, Rosell F. The forgotten prey of an iconic predator: a review of interactions between grey wolves Canis lupus and beavers Castor spp. Mammal Rev. 2018;48(2):123-38.

92. Fryxell JM, Doucet CM. Diet choice and the functional response of beavers. Ecology. 1993;74(5):1297-306.

93. Gable TD, Windels SK, Bruggink JG, Homkes AT. Where and How Wolves (Canis lupus) Kill Beavers (Castor canadensis). PLoS ONE. 2016;11(12):e0165537.

94. Law A, Gaywood MJ, Jones KC, Ramsay P, Willby NJ. Using ecosystem engineers as tools in habitat restoration and rewilding: beaver and wetlands. Sci Total Environ. 2017;605-606:1021-30.

95. Gable TD, Homkes AT, Johnson-Bice SM, Windels SK, Bump JK. Wolves choose ambushing locations to counter and capitalize on the sensory abilities of their prey. Behav Ecol. 2021;32:339-48.

96. Gurnell AM. The hydrogeomorphological effects of beaver dam-building activity. Prog Phys Geogr. 1998;22(2):167-89.

97. Woo M-K, Waddington JM. Effects of beaver dams on subarctic wetland hydrology. Arctic. 1990;43:223-30.

98. Severud WJ, Belant JL, Windels SK, Bruggink JG. Seasonal variation in assimilated diets of American beavers. Am Midland Nat. 2013:169:30-42

99. Graf PM, Wilson RP, Sanchez LC, Hackländer K, Rosell F. Diving behavior in a free-living, semi-aquatic herbivore, the Eurasian beaver Castor fiber. Ecol Evol. 2018;8(2):997-1008.

100. Fish FE. Biomechanics and energetics in aquatic and semiaquatic mammals: platypus to whale. Physiol Biochem Zool. 2000;73(6):683-98.

101. Allers D, Culik BM. Energy requirements of beavers (Castor canadensis) swimming underwater. Physiol Zool. 1997;70(4):456-63.

102. Fish FE. Comparison of swimming kinematics between terrestrial and semiaquatic opossums. J Mamm. 1993;74(2):275-84.

103. Pinto B, Santos MJ, Rosell F. Habitat selection of the Eurasian beaver (Castor fiber) near its carrying capacity: an example from Norway. Can J Zool. 2009;87(4):317-25.

104. Olstad O. Beverens (Castor fiber) utbredelse i Norge. Statens viltundersøkelser. 1937;77:217-73.

105. Herfindal I, Linnell JD, Odden J, Nilsen EB, Andersen R. Prey density, environmental productivity and home-range size in the Eurasian lynx (Lynxlynx). J Zool. 2005;265(1):63-71.

106. Rosell F, Hovde B. Methods of aquatic and terrestrial netting to capture Eurasian beavers. Wildl Soc Bull. 2001;29(1):269-74.

107. Rosell F, Sun L. Use of anal gland secretion to distinguish the two beaver species Castor canadensis and C. fiber. Wildl Biol. 1999;5(2):119-23.

108. Rosell F, Zedrosser A, Parker H. Correlates of body measurements and age in Eurasian beaver from Norway. Eur J Wildl Res. 2010;56(1):43-8.

109. Mayer M, Künzel F, Zedrosser A, Rosell F. The 7-year itch: nonadaptive mate change in the Eurasian beaver. Behav Ecol Sociobiol. 2017;71(2):32

110. Fleming $\mathrm{CH}$, Fagan WF, Mueller T, Olson KA, Leimgruber P, Calabrese JM. Rigorous home range estimation with movement data: a new autocorrelated kernel density estimator. Ecology. 2015;96(5):1182-8.

111. Walker JS, Jones MW, Laramee RS, Holton MD, Shepard EL, Williams HJ, Scantlebury DM, Marks NJ, Magowan EA, Maguire IE, Bidder OR, Di Virgilio A, Wilson RP. Prying into the intimate secrets of animal lives; software beyond hardware for comprehensive annotation in "Daily Diary" tags. Mov Ecol. 2015;3(1):29

112. Lewis JS, Rachlow JL, Garton EO, Vierling LA. Effects of habitat on GPS collar performance: using data screening to reduce location error. J Appl Ecol. 2007;44(3):663-71.

113. Justicia LS, Rosell F, Mayer M. Performance of GPS units for deployment on semiaquatic animals. PLOS ONE. 2018:13(12):e0207938.

114. Middelboe AL, Markager S. Depth limits and minimum light requirements of freshwater macrophytes. Freshw Biol. 1997;37(3):553-68.

115. Artsdatabanken. Artsnavnebase. Norsk taksonomisk database; 2015 http://www2.artsdatabanken.no/artsnavn/Contentpages/Sok.aspx. Accessed 4 Feb 2020
116. Kent M. Vegetation description and data analysis: a practical approach. Chichester: John Wiley \& Sons; 2012.

117. Oksanen J, Blanchet FG, Kindt R, Legendre P, Minchin PR, O'hara R, Simpson GL, Solymos P, Stevens MHH, Wagner H. Package 'vegan'. Community ecology package, version 2.5-7; 2013.

118. Lele SR, Merrill EH, Keim J, Boyce MS. Selection, use, choice and occupancy: clarifying concepts in resource selection studies. J Anim Ecol. 2013;82(6):1183-91.

119. Gillies CS, Hebblewhite M, Nielsen SE, Krawchuk MA, Aldridge CL, Frair JL, Saher DJ, Stevens CE, Jerde CL. Application of random effects to the study of resource selection by animals. J Anim Ecol. 2006;75(4):887-98.

120. Zuur AF, leno EN, Walker NJ, Saveliev AA, Smith GM. Mixed effects models and extensions in ecology with R. New York: Spring Science and Business Media; 2009.

121. Burnham KP, Anderson DR. Model selection and multimodel inference: a practical information-theoretic approach. New York: Springer Science \& Business Media; 2002.

122. Magnusson A, Skaug H, Nielsen A, Berg C, Kristensen K, Maechler M, van Bentham K, Bolker B, Brooks M, Brooks MM. Package 'glmmTMB'. R package version 1.0.2.1; 2017

123. Barton K. MuMIn: Multi-Model Inference. R package version 1.43.17; 2018

124. Arnold TW. Uninformative parameters and model selection using Akaike's Information Criterion. J Wildl Manag. 2010;74(6):1175-8.

125. Hartig F. DHARMa: residual diagnostics for hierarchical (multi-level/ mixed) regression models. $R$ package version $0.4 .1 ; 2017$.

126. Team RC. R: a language and environment for statistical computing, $r$ foundation for statistical computing, Austria; 2015, 2018.

127. Lardet J-P. Spatial behaviour and activity patterns of the water shrew Neomys fodiens in the field. Acta Theriol. 1988;33(21):293-303.

128. Hays GC, Forman DW, Harrington LA, Harrington AL, MacDonald DW, Righton D. Recording the free-living behaviour of small-bodied, shallow-diving animals with data loggers. J Anim Ecol. 2007;76(1):183-90.

129. Harrington LA, Hays GC, Fasola L, Harrington AL, Righton D, Macdonald DW. Dive performance in a small-bodied, semi-aquatic mammal in the wild. J Mamm. 2012;93(1):198-210.

130. Bagniewska JM, Harrington LA, Hart T, Harrington AL, Fasola L, Macdonald DW. Persistence in diving American mink. Anim Biotelemetry. 2015;3(1):1-10.

131. Vogel P, Bodmer C, Spreng M, Aeschimann J, Dunstone N, Gorman M. Diving capacity and foraging behaviour of the water shrew. Cambridge: Cambridge University Press; 1998.

132. Ciancio JE, Quintana F, Sala JE, Wilson RP. Cold birds under pressure: can thermal substitution ease heat loss in diving penguins? Mar Biol. 2016;163(2):43

133. Wilson RP, Hustler K, Ryan PG, Burger AE, Noldeke EC. Diving birds in cold water: do Archimedes and Boyle determine energetic costs? Am Nat. 1992;140(2):179-200.

134. Wilson RP, Borger L, Holton MD, Scantlebury DM, Gomez-Laich A, Quintana F, Rosell F, Graf PM, Williams H, Gunner R, Hopkins L, Marks N, Geraldi NR, Duarte CM, Scott R, Strano MS, Robotka H, Eizaguirre C, Fahlman A, Shepard ELC. Estimates for energy expenditure in freeliving animals using acceleration proxies: a reappraisal. J Anim Ecol. 2020;89(1):161-72.

135. Wilson RP, Shepard EL, Laich AG, Frere E, Quintana F. Pedalling downhill and freewheeling up; a penguin perspective on foraging. Aquat Biol. 2010;8(3):193-202

136. Perrow MR, Schutten JH, Howes JR, Holzer T, Madgwick FJ, Jowitt AJ. Interactions between coot (Fulica atra) and submerged macrophytes: the role of birds in the restoration process. Shallow Lakes' 95. Berlin: Springer; 1997. p. 241-55.

137. Irwin S, O'Halloran J, editors. The wintering behaviour of coot Fulica atra L. at Cork Lough, south-west Ireland. In: Biology and environment: proceedings of the royal Irish academy. JSTOR; 1997.

138. Bagniewska JM, Hart T, Harrington LA, Macdonald DW. Hidden Markov analysis describes dive patterns in semiaquatic animals. Behav Ecol. 2013;24(3):659-67.

139. De Leeuw JJ. Food intake rates and habitat segregation of tufted duck Aythya fuligula and scaup Aythya marila exploiting zebra mussels Dreissena polymorpha. Ardea. 1999;87(1):15-31. 
140. Fish FE, Smelstoys J, Baudinette RV, Reynolds PS. Fur doesn't fly, it floats: buoyancy of pelage in semi-aquatic mammals. Aquat Mamm. 2002;28(2):103-12.

141. Harrington LA, Harrington AL, Yamaguchi N, Thom MD, Ferreras $P$, Windham TR, Macdonald DW. The impact of native competitors on an alien invasive: temporal niche shifts to avoid interspecific aggression. Ecology. 2009;90(5):1207-16.

142. Theuerkauf J, Jegdrzejewski W, Schmidt K, Okarma H, Ruczyński I, Śniezko S, Gula R. Daily patterns and duration of wolf activity in the Białowieza Forest. Poland J Mammal. 2003;84(1):243-53.

143. Rodriguez-Ramos Fernandez J, Dubielzig RR. Ocular comparative anatomy of the family Rodentia. Vet Ophthalmol. 2013;16:94-9.

144. Campbell-Palmer R, Rosell F. Conservation of the Eurasian beaver Castor fiber: an olfactory perspective. Mamm Rev. 2010;40(4):293-312.

145. Ollivier F, Samuelson D, Brooks D, Lewis P, Kallberg M, Komáromy A. Comparative morphology of the Tapetum lucidum (among selected species). Vet Ophthalmol. 2004;7(1):11-22.

146. Maffei L, Fiorentini A, Bisti S. The visual acuity of the lynx. Vision Res. 1990;30(4):527-8.

147. Swinnen KRR, Hughes NK, Leirs H. Beaver (Castor fiber) activity patterns in a predator-free landscape. What is keeping them in the dark? Mamm Biol. 2015;80(6):477-83.

148. Birt V, Birt T, Goulet D, Cairns D, Montevecchi W. Ashmole's halo: direct evidence for prey depletion by a seabird. Mar Ecol Progr Ser Oldendorf. 1987;40(3):205-8.

149. Elliott KH, Woo KJ, Gaston AJ, Benvenuti S, Dall'Antonia L, Davoren GK. Central-place foraging in an Arctic seabird provides evidence for StorerAshmole's halo. Auk. 2009;126(3):613-25.

150. Nolet BA, Rosell F. Territoriality and time budgets in beavers during sequential settlement. Can J Zool. 1994;72(7):1227-37.

151. Lima SL. Ecological and evolutionary perspectives on escape from predatory attack: a survey of North American birds. The Wilson Bulletin. 1993;105(1):1-47.

152. Orians $\mathrm{GH}$, Pearson NE. On the theory of central place foraging. In: Horn DJ, Mitchell RD, Stairs GR, editors. Analysis of ecological systems. Columbus: The Ohio State University Press; 1979. p. 154-77.

153. Wetterer JK. Central place foraging theory: when load size affects travel time. Theor Popul Biol. 1989;36(3):267-80.

154. Houston Al, MCNamara JM. A general theory of central place foraging for single-prey loaders. Theor Popul Biol. 1985;28(3):233-62.

155. DuPasquier A, Cantoni D. Shifts in benthic macroinvertebrate community and food habits of the water shrew, Neomys fodiens (Soricidae, Insectivora). Acta Oecol. 1992;13(1):81-99.

156. Goryainova Z, Katsman E, Zavyalov N, Khlyap L, Petrosyan V. Evaluation of tree and shrub resources of the Eurasian beaver (Castor fiber L.) and changes in beaver foraging strategy after resources depletion. Russ J Biol Invas. 2014;5(4):242-54.

157. Danilov P, Fyodorov F. Comparative characterization of the building activity of Canadian and European beavers in northern European Russia. Russ J Ecol. 2015;46(3):272-8.

158. Collen P, Gibson R. The general ecology of beavers (Castor spp.), as related to their influence on stream ecosystems and riparian habitats, and the subsequent effects on fish - a review. Rev Fish Biol Fish. 2000;10(4):439-61.
159. Nolet BA, Rosell F. Comeback of the beaver Castor fiber: An overview of old and new conservation problems. Biol Cons. 1998;83(2):165-73.

160. Macdonald DW, Tattersall F, Brown E, Balharry D. Reintroducing the European beaver to Britain: nostalgic meddling or restoring biodiversity? Mamm Rev. 1995;25(4):161-200.

161. Andersen DC, Shafroth PB. Beaver dams, hydrological thresholds, and controlled floods as a management tool in a desert riverine ecosystem, Bill Williams River. Arizona Ecohydrol. 2010;3(3):325-38.

162. Nolet BA, Hoekstra A, Ottenheim MM. Selective foraging on woody species by the beaver Castor fiber, and its impact on a riparian willow forest. Biol Cons. 1994;70(2):117-28.

163. Logan M, Sanson GD. The effects of lactation on the feeding behaviour and activity patterns of free-ranging female koalas (Phascolarctos cinereus Goldfuss). Aust J Zool. 2003:51(4):415-28.

164. Zoller H, Drygala F. Activity patterns of the invasive raccoon dog (Nyctereutes procyonoides) in North East Germany. J Vertebr Biol. 2013;62(4):290-6.

165. Cantoni D. Social and spatial organization of free-ranging shrews, Sorex coronatus and Neomys fodiens (Insectivora, Mammalia). Anim Behav. 1993:45(5):975-95.

166. Lodberg-Holm HK, Steyaert S, Reinhardt S, Rosell F. Size is not everything: differing activity and foraging patterns between the sexes in a monomorphic mammal. Behav Ecol Sociobiol. 2021;75(4):1-14.

167. Mayer M, Zedrosser A, Rosell F. Couch potatoes do better: Delayed dispersal and territory size affect the duration of territory occupancy in a monogamous mammal. Ecol Evol. 2017;7(12):4347-56.

168. Mayer M, Fog Bjerre DH, Sunde P. Better safe than sorry: The response to a simulated predator and unfamiliar scent by the European hare. Ethology. 2020;126(7):704-15.

169. Benkwitt CE. Central-place foraging and ecological effects of an invasive predator across multiple habitats. Ecology. 2016;97(10):2729-39.

170. Dale S, Gustavsen R, Slagsvold T. Risk taking during parental care: a test of three hypotheses applied to the pied flycatcher. Behav Ecol Sociobiol. 1996;39(1):31-42

171. Chimienti M, Cornulier T, Owen E, Bolton M, Davies IM, Travis JMJ, Scott BE. The use of an unsupervised learning approach for characterizing latent behaviors in accelerometer data. Ecol Evol. 2016;6(3):727-41.

172. Gunner RM, Wilson RP, Holton MD, Scott R, Hopkins P, Duarte CM. A new direction for differentiating animal activity based on measuring angular velocity about the yaw axis. Ecol Evol. 2020;10(14):7872-86.

173. Buchanan K, Burt de Perera T, Carere C, Carter T, Hailey A, Hubrecht R, Jennings D, Metcalfe N, Pitcher T, Peron F. Guidelines for the treatment of animals in behavioural research and teaching. Anim Behav. 2012;83(1):301-9.

174. Kilkenny C, Browne WJ, Cuthill IC, Emerson M, Altman DG. Improving bioscience research reporting: the ARRIVE guidelines for reporting animal research. PLoS Biol. 2010;8(6):e1000412.

\section{Publisher's Note}

Springer Nature remains neutral with regard to jurisdictional claims in published maps and institutional affiliations.

Ready to submit your research? Choose BMC and benefit from

- fast, convenient online submission

- thorough peer review by experienced researchers in your field

- rapid publication on acceptance

- support for research data, including large and complex data types

- gold Open Access which fosters wider collaboration and increased citations

- maximum visibility for your research: over $100 \mathrm{M}$ website views per year

At BMC, research is always in progress.

Learn more biomedcentral.com/submissions 